\title{
Thermal design of large plate-fin heat exchanger for cryogenic air separation unit
}

\section{based on multiple dynamic equilibriums}

\author{
XU Jing-hua CHEN Xiao-jie ZHANG Shu-you CHEN Qian-yong GOU Hua-wei TAN Jian-rong
}

(State Key Lab of Fluid Power and Mechatronic Systems, Zhejiang University, Hangzhou 310027)

\begin{abstract}
This paper presents a thermal design method of large plate-fin heat exchanger (PFHE) for cryogenic air separation unit (ASU) based on multiple dynamic equilibriums (MDE). The enlarging of PFHE brings cascading thermal design difficulties. Renault number of multi-streams in long passages fluctuates in wide range which generates various working conditions. The fin type of each passage and the Re for flowing streams are pre-set firstly. Using single-banking with top priority, the Recursive Prior Plug-In (RPP) method is proposed to complete permutation of hot streams and cold streams. The preferable passage arrangement is selected and determined according to the variance of the cumulative heat load. The initial temperature of each ordered stream in all the passages is then obtained. The temperature difference sequence between the one-sided adjacent streams is built. The large heat transfer area in plane perpendicular to the flowing direction is divided into MDE according to the temperature difference sequence. For each equilibrium, the heat balance equations between hot quantity and cold quantity are built by Fourier's law of heat conduction and heat convection. The final equilibrium temperature of each ordered stream in all the passages can be obtained by iterative solving the simultaneous differential equations for all MDE. Each long stream is also divided into MDE along flowing direction and modelled by energy conservation principle in enthalpy change to obtain the actual phase. The heat transfer process about Re is divided into MDE according to the dynamic equilibriums between heat transfer and frictional resistance to determine the optimal fins under different working conditions. The heat transfer experiment is completed to verify the proposed method. The MDE is applicable for various stacking patterns of numerous long hot streams and cold streams under variable working conditions. The proposed method is especially useful for thermal design of large energy-efficient PFHE for ASU.
\end{abstract}

Key words: Cryogenic air separation unit (ASU); Large plate fin heat exchanger (PFHE); Thermal Design; Multiple Dynamic Equilibriums (MDE); Stacking Pattern; Working Condition

\section{Introduction}

The cryogenic air separation unit (ASU) separates atmospheric air into oxygen, nitrogen, argon and rarely other noble inert gases. Stimulated by the increasing needs for ASU throughout the industry, the trend of ASU is high productivity with remarkable energy-efficiency ${ }^{[1][2]}$. The plate fin heat exchanger (PFHE) transfers heat by condensation, evaporation and liquefaction for ASU. The thermal efficiency of PFHE has remarkable effects on energy-efficiency of $\mathrm{ASU}^{[3]}$.

In recent years, many papers ${ }^{[4][5][6]}$ focus on heat transfer modeling, thermal efficiency, heat transfer experiment, simulation and visualization, optimization design. 
Among them, in stacking pattern research ${ }^{[7]}$, Prasad ${ }^{[8][9]}$ researched the multistream PFHE based on stacking pattern of stream passages. Ghosh et al. ${ }^{[10]}$ proposed optimum stacking pattern for multi-stream PFHE through a genetic algorithm. Zhao et al. ${ }^{[11]}$ studied layer pattern optimization model for multi-stream plate-fin heat exchanger using genetic algorithm.

In thermal modeling, simulation and visualization research, Ref.[12] built multidimensional numerical model of heat exchanger. Hasan et al. ${ }^{[13]}$ researched operational modeling of multistream heat exchangers with phase changes. Hajabdollahi et al. ${ }^{[14]}$ proposed CFD modeling and multi-objective optimization method of compact heat exchanger using CAN method. Ref. ${ }^{[15]}$ modeled and simulated rectangular plain fin, strip offset fin, perforated fin, and wavy fin. Speetjens et al. ${ }^{[16]}$ studied visualisation of heat transfer in 3D unsteady flows.

In thermal experimental research, Ref. ${ }^{[17]}$ studied configuration parameters design and optimization for PFHE with serrated fin by multi-objective genetic algorithm. Khan et al. ${ }^{[18]}$ introduced experimental investigation of single phase convective heat transfer coefficient in a corrugated plate heat exchanger for multiple plate configurations. Gherasim et al. ${ }^{[19]}$ studied heat transfer and fluid flow experiment. Kotcioglu et al. ${ }^{[20]}$ researched experimental investigation for optimization of design parameters in a rectangular duct with plate-fins heat exchanger by Taguchi method.

In thermal optimization design, Ghosh et al. ${ }^{[21]}$ studied alternate algorithm for the analysis of multi-stream. Reneaume et al. ${ }^{[22]}$ proposed simulated annealing optimization method for PFHE. Ref.[23] introduced neural networks method cooperated with genetic algorithms optimization. Najafi et al. ${ }^{[2]}$ proposed multi-objective optimization of a plate and frame heat exchanger via genetic algorithm. Yousefi et al. ${ }^{[25][26]}$ proposed an imperialist competitive algorithm and an improved harmony search algorithm for optimal design of PFHE. Zarea et al. ${ }^{[27]}$ studied optimal design of PFHE by a Bees Algorithm. Hajmohammadi et al. ${ }^{[28]}$ studied optimal design of unequal heat flux elements for optimized heat transfer inside a rectangular duct. Montanez-Morantes et al. ${ }^{[29]}$ simulated single-phase multistreams in PFHE. Turgut ${ }^{[30]}$ proposed hybrid chaotic quantum behaved particle swarm optimization algorithm for thermal design of PFHE. 
In Ref. [31], the mean square error of cumulative heat load is reduced. Ref. [32] studied serrated fin by multi-objective genetic algorithm.

In conclusion, the above papers promote the research of PFHE in either theory or experiment. Most published studies are based on the assumption that there exist thermal equilibrium between the two adjacent streams. The assumption is feasible for the single-banking of few streams. However, the enlarging of PFHE brings cascading thermal design difficulties. Renault number of multi-streams in long passages fluctuates in wide range which generates various working conditions. Various stacking patterns including multiple-banking and hybrid-banking are inevitably used to complete passage arrangement. It is difficult to complete design of large PFHE by simply using the current methods. Therefore, a thermal design method of large plate-fin heat exchanger (PFHE) for cryogenic air separation unit (ASU) based on multiple dynamic equilibriums (MDE) is proposed and verified by experiment.

\section{Design difficulties caused by enlarging of PFHE for cryogenic ASU}

\subsection{Cryogenic air separation unit and the heat exchange sub-system}

Cryogenic ASU use the continuous process of stream compression, cooling, liquefaction and distillation. The cryogenic ASU mainly includes submachines which are air compressor (Label 2 in Fig.1), turbo expander (Labels 8, 9), heat exchanger (Labels 11,12,14), distillation packing tower (Labels 13,15,16,17). The ASU process mainly contains adsorption subsystem, rectification subsystem and heat exchange subsystem. The adsorption subsystem is used to remove impurities such as water, carbon dioxide, hydrocarbons, acetylene. The adsorption of $\mathrm{CO}_{2}$ content should be less than $1 \mathrm{ppm}$ (part per million, $1 \mathrm{ppm}=1 \mathrm{e}-6$ ). The rectification subsystem is used to extract the different fractions of air according to the different boiling points.

The heat exchange subsystem functions as condensation, evaporation and liquefaction of hot and cold multi-streams. Heat exchange sub-system of ASU includes main heat exchanger (Label 11), subcooler (Label 12) and condenser evaporator (Label 14). In main heat exchanger, hot streams top-down also called forwards flow and cold 
streams bottom up also called backwards flow exchange heat via countercurrent heat transfer. In subcooler, liquid air and liquid nitrogen are further cooled below the saturation temperature by gaseous nitrogen and waste nitrogen via countercurrent flow. In condenser evaporator, liquid oxygen falling from upper column evaporates and gaseous nitrogen rising from lower column condensates via phase change heat transfer.

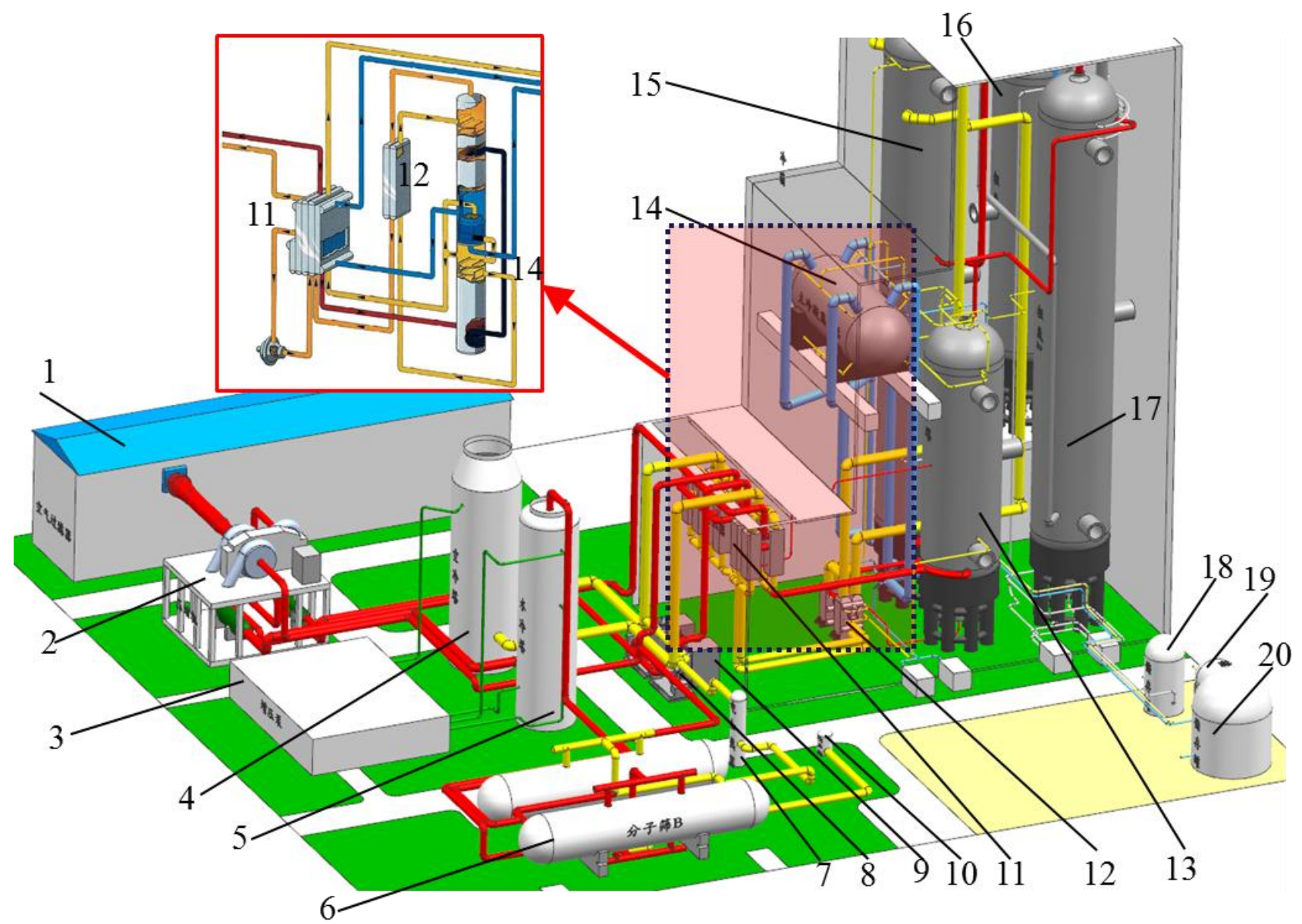

1. self-cleaning air filter; 2. air compressor; 3. water pump; 4. air cooling tower; 5. water-cooling tower; 6. molecular sieve absorber; 7. electric heater; 8. Supercharger; 9. turbo-expander; 10. silencer; 11. main heat exchanger; 12. Subcooler; 13. lower column; 14. main condenser evaporator; 15. upper column; 16. crude argon column I ; 17. crude argon column II ; 18. liquid argon pump; 19. liquid argon; 20. gaseous nitrogen.

Fig.1. PFHE functions as condensation, evaporation and liquefaction for ASU

\subsection{Large Plate-fin heat exchanger and the design challenges}

Large PFHE which is also called Brazed Aluminum Plate-Fin Heat Exchanger (BAHX) or Brazed plate heat exchangers (BPHE) consists of a stack of alternate flat plates called "parting sheets" and fin corrugations, brazed together as a block shown in 
Fig.2. The streams flow along the passages made by the corrugations between the parting sheets. The corrugations serve as both secondary heat transfer surfaces and mechanical supports for the internal pressures between layers. The direction of width, height and length of PFHE is generally defined via the finned passage of core.
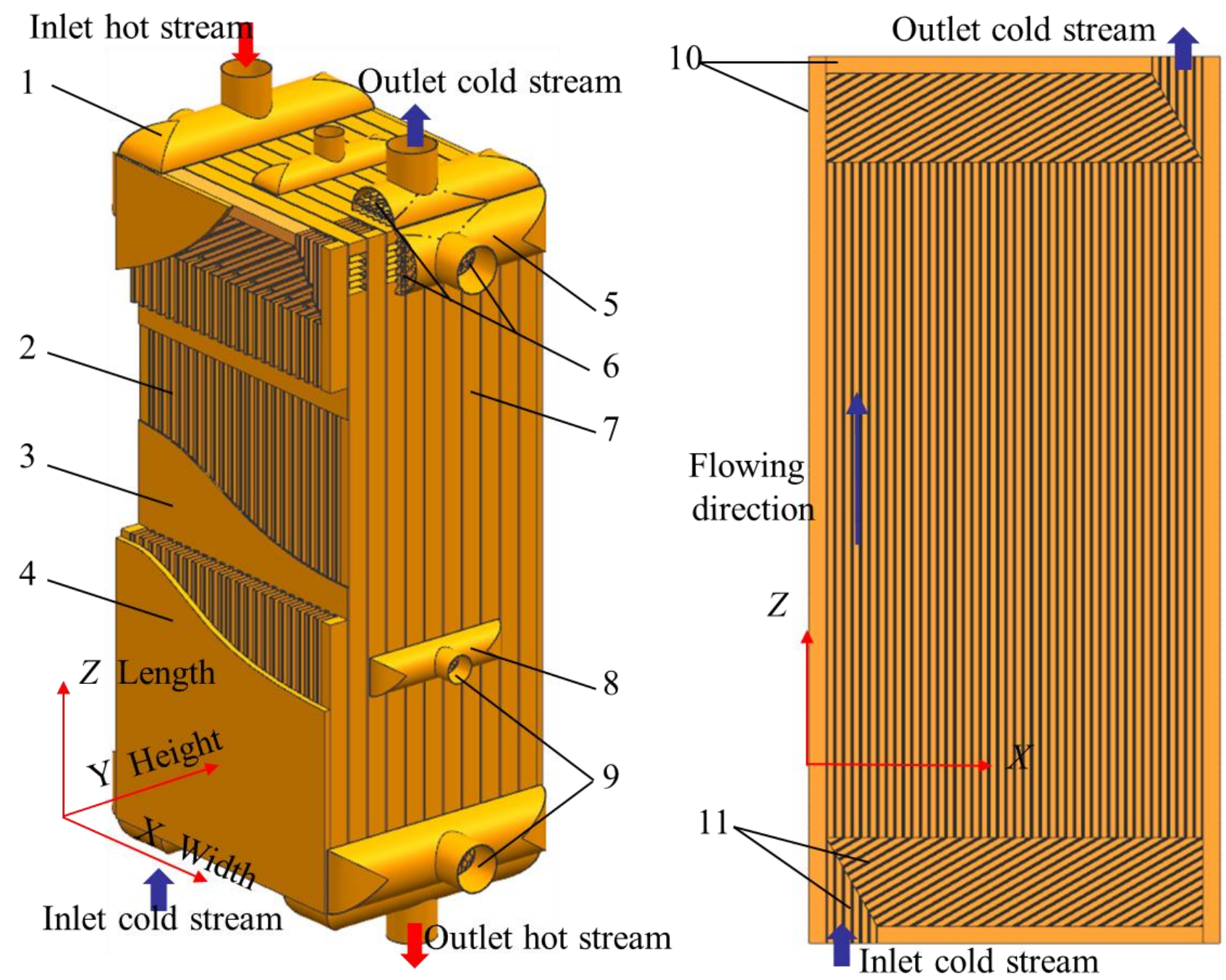

1. End header; 2.Layer or passage of heat transfer fins; 3.Parting sheet; 4. Side cap sheet; 5.Side header; 6. Flow equalizing wing; 7. Block (core); 8.Intermediate header; 9.Nozzles; 10.Side bars; 11.Distributor fins

Fig.2. Multi-stream vertical brazed aluminum plate-fin heat exchanger (PFHE)

The enlarging of PFHE causes cascading design difficulties. For example, width $(\mathrm{W})(x) \times$ height $(\mathrm{H})(y) \times$ length $(\mathrm{L})(z)$ may be more than $6.0 \mathrm{~m} \times 3.0 \mathrm{~m} \times 10.0 \mathrm{~m}$; the number of passage may be more than 100 ; the pressure may be more than $9 \mathrm{MPa}$ $(1 \mathrm{MPa}=10 \mathrm{bar} \approx 145 \mathrm{psi})$; permissible temperature differences between adjacent streams should be less than $10 \mathrm{~K}$; surface area density, area/volume may be $1500 \mathrm{~m}^{2} / \mathrm{m}^{3}$. The 
long flowing length $(z)$ of layer may cause phase change for the stream. Multiple banking of passage arrangement will reduce thermal efficiency. How to solve these design challenges and obtain optimal equilibrium is an important research hotspot.

\subsection{Surface efficiency and effective heat transfer area of different fins}

Heat is energy in transit. The basic heat transfer equation

$$
q=\frac{d Q}{d t}=A q_{A}=\int_{0}^{A} K \Delta T d A \approx K \Delta T_{m} A
$$

where $Q$ is heat transferred $(\mathrm{J}) ; q$ is heat transfer rate $(\mathrm{W}) ; A$ is heat surface area $\left(\mathrm{m}^{2}\right) ; q_{A}$ is heat flux $\left(\mathrm{W} \cdot \mathrm{m}^{-2}\right) ; K$ is heat transfer coefficient $\left(\mathrm{W} \cdot \mathrm{m}^{-2} \cdot \mathrm{K}^{-1}\right) ; \Delta T$ is temperature difference, $(\mathrm{K}) ; \Delta T_{m}$ is mean temperature difference (MTD), which depends upon the flow configurations of the streams.

Heat is transferred from or into a stream within a finned passage. Fins are the basic components of PFHE. The fin types include plain (straight), wavy (corrugated) fin, serrated (offset, OSF) fin, perforated fin, louvered fin, etc. The fins can also be further subdivided into rectangular fin, triangular fin, pin fin, herringbone fin, etc. The heat transfer surface area per meter in $Z$ direction can be classified into primary heat transfer surface $A_{1}$ and secondary heat transfer surface $A_{2} . A_{1}$ is provided by the bare parting sheet and the fin base directly brazed to the parting sheet. $A_{2}$ is provided by the fins. The ratio $A_{2} /\left(A_{1}+A_{2}\right)$ of $A_{2}$ to the total $A_{1}+A_{2}$ represents the ratio of heat transferred along direction of fin height to the total heat transfer surface area

$$
\begin{aligned}
A_{1} & =2\left(1-d_{f} t_{f}\right) \\
A_{2} & =2 d_{f}\left(h_{f}-t_{f}\right) \\
\frac{A_{2}}{A_{1}+A_{2}} & =\frac{d_{f}\left(h_{f}-t_{f}\right)}{\left(1-d_{f} t_{f}\right)+d_{f}\left(h_{f}-t_{f}\right)}
\end{aligned}
$$

where $h_{f}$ is the fin height $(\mathrm{mm}) ; t_{f}$ is the fin thickness $(\mathrm{mm}) ; p_{f}$ is fin 
pitch/spacing $(\mathrm{mm}) ; d_{f}$ is the fin density $d_{f}=p_{f}^{-1}\left(\mathrm{~m}^{-1}\right)$, i.e. number of fins per meter in $X$ direction.

For different types of fins shown in Fig. $3, l_{\mathrm{p}}$ is wave length for wavy fins or tooth length for OSF fins. The fin type determines the cross-section of the passage which can be rectangle, circle, annulus, etc. The equivalent diameter $d_{e}$ can be obtained by cross section area $A$ and section perimeter $l$, for rectangle without fillet

$$
\begin{gathered}
A=d_{f}\left(h_{f}-t_{f}\right)\left(p_{f}-t_{f}\right) \\
l=d_{f}\left(2\left(h_{f}-t_{f}\right)+2\left(p_{f}-t_{f}\right)\right) \\
d_{\mathrm{e}}=4 \frac{A}{l}=4 \frac{d_{f}\left(h_{f}-t_{f}\right)\left(p_{f}-t_{f}\right)}{d_{f}\left(2\left(h_{f}-t_{f}\right)+2\left(p_{f}-t_{f}\right)\right)}=\frac{2\left(h_{f}-t_{f}\right)\left(p_{f}-t_{f}\right)}{\left(h_{f}-t_{f}\right)+\left(p_{f}-t_{f}\right)} \\
l * Z=A_{1}+A_{2}
\end{gathered}
$$

The Renault number $R e$ for flowing stream is defined by

$$
R e=\frac{u d_{e}}{v}=\frac{\rho u d_{e}}{\mu}=\frac{\dot{V}}{A} \frac{\rho d_{e}}{\mu}=\frac{\dot{m} d_{e}}{A \mu}
$$

where $u$ is fluid velocity $\left(\mathrm{m} \cdot \mathrm{s}^{-1}\right) ; v$ is kinematic viscosity $\left(\mathrm{m}^{2} \cdot \mathrm{s}^{-1}\right) ; \mu$ is dynamic viscosity $(\mathrm{Pa} \cdot \mathrm{s}) ; \rho$ is mass density in standard state $\left(\mathrm{kg} \cdot \mathrm{m}^{-3}\right) ; \quad \dot{V}$ is the volume flow rate of stream in standard normal state $\left(\mathrm{Nm}^{3} \cdot \mathrm{s}^{-1}\right) ; \dot{m}$ is mass flow rate in standard state $\left(\mathrm{kg} \cdot \mathrm{s}^{-1}\right)$.

Obviously, $R e$ is the core parameter used to determine the working condition of convective heat transfer between multi-streams.

Fin efficiency $\eta_{f}$ is defined as the ratio of actual transferred heat to ideal transferred heat. The $\eta_{f}$ is not connected with flow configurations. Using basic heat transfer Eq.(1),

$$
\eta_{f}=\frac{Q_{\text {actual }}}{Q_{\text {ideal }}}=\frac{\int_{0}^{A} K \Delta T_{\text {fin }} d A}{\int_{0}^{A} K \Delta T_{\text {sheet }} d A} \approx \frac{\overline{T_{\text {fin }}}-T_{\text {stream }}}{\overline{T_{\text {sheet }}-T_{\text {stream }}}} \in(0,1)
$$


where $\overline{T_{\text {fin }}}$ is mean temperature of the fins $(\mathrm{K}) ; \overline{T_{\text {sheet }}}$ is mean temperature of sheet along the flowing direction (K).

The temperature $T_{f i n}(x)$ depends on the type and shape of the fin. For circular fin with equal cross-section, $T_{\text {fin }}(x)$ obeys Bessel's differential equation. For straight fin with equal cross-section, $T_{\text {fin }}(x)$ obeys hyperbolic function "tanh"

$$
T_{f i n}(x) \sim \tanh (\mathrm{x})=\frac{\sinh (\mathrm{x})}{\cosh (\mathrm{x})}=\frac{e^{x}-e^{-x}}{e^{x}+e^{-x}} \in(-1,1) \quad x \in \mathrm{R}
$$

Surface efficiency $\eta_{s}$ is defined as the comprehensive efficiency of $A_{1}$ and $A_{2}$. The total transferred heat $Q$ equals to the primary transferred heat $Q_{1}$ and secondary transferred heat $Q_{2}$.

$$
\begin{gathered}
Q=Q_{1}+Q_{2} \\
K\left(A_{1}+A_{2}\right) \eta_{s} \Delta T=K A_{1} \Delta T+K A_{2} \eta_{f} \Delta T \\
\eta_{s}=1-\frac{A_{2}}{A_{1}+A_{2}}\left(1-\eta_{f}\right)
\end{gathered}
$$

Surface efficiency $\eta_{s}$ can be used to obtain effective heat transfer area $A_{e}$.

$$
A_{e}=A \eta_{s}
$$



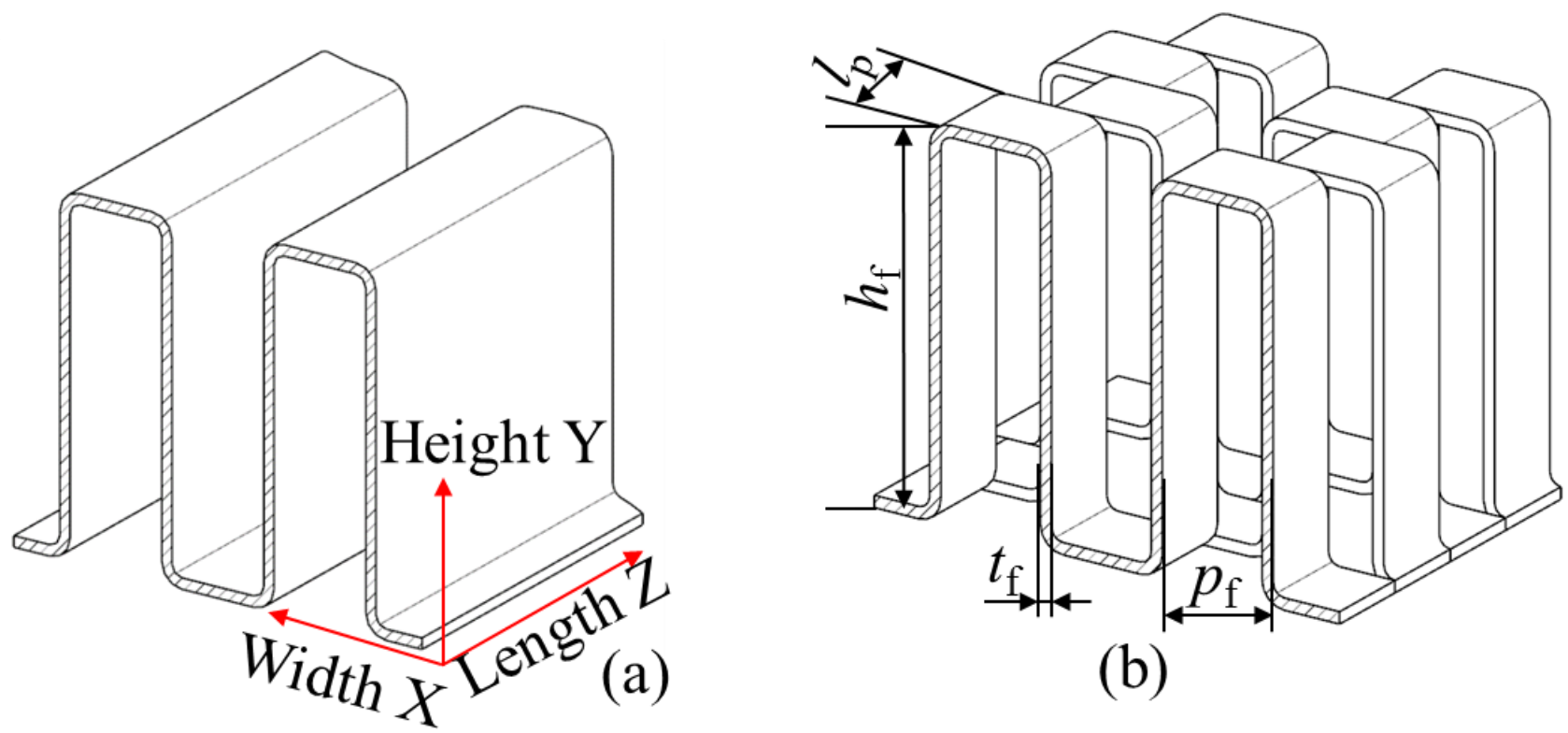

(b)

\section{Primary heat transfer area $\mathrm{A}_{1}$}
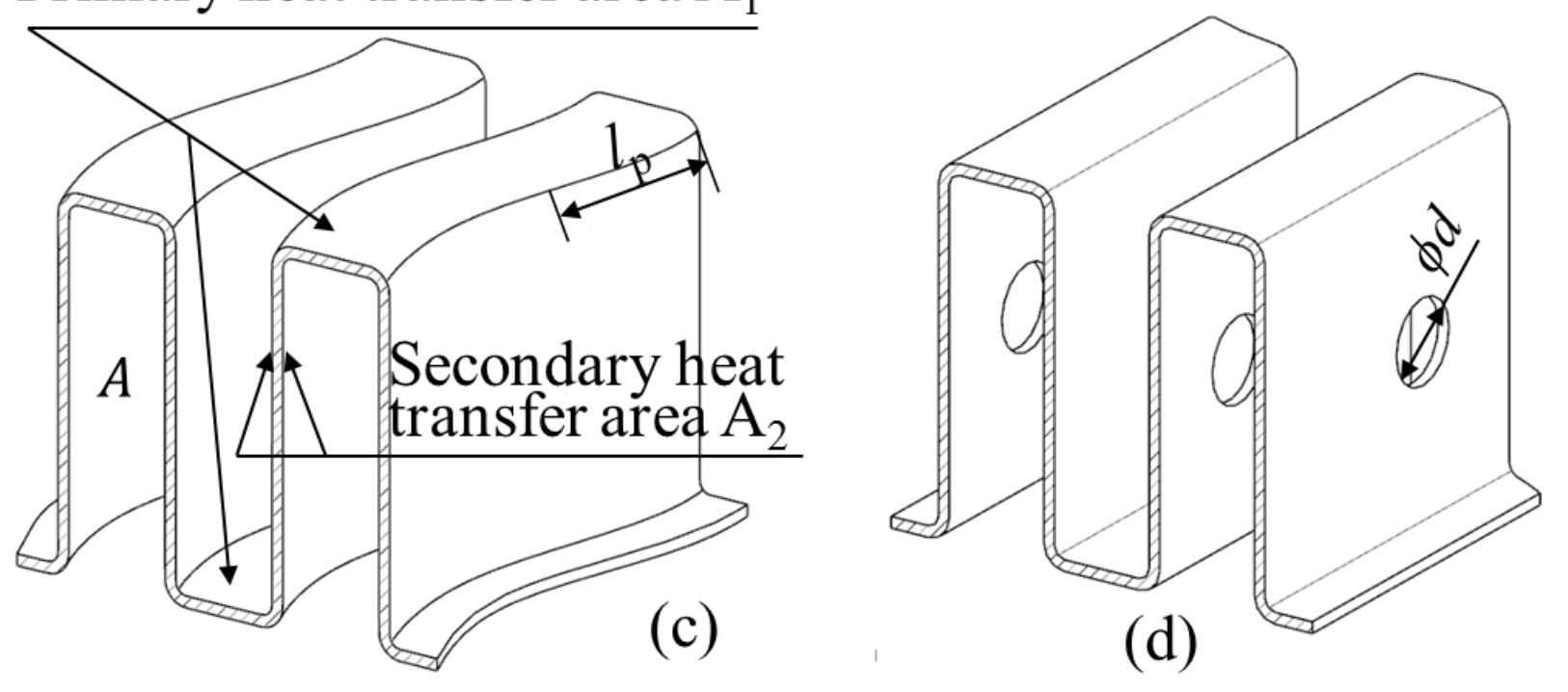

Fig.3. Geometric parameters of plain fin, serrated fin, wavy fin and perforated fin

\section{Divide large heat transfer area in various directions into MDE for PFHE}

\subsection{Aarranging various kinds and types of streams into passages using RPP}

Large PFHE has $n$ passages, namely $n+1$ sheets, ascending ordered from bottom to top. According to cryogenic process of ASU shown in Fig.1, there are two kinds and $N_{\text {type }}$ types of streams in the $n$ passages. The PFHE transfers heat between hot streams and cold streams which involves at least two streams and 
passages, $n \geq N_{\text {type }} \geq 2$. The total number $N_{j}$ of passages for $j$-th type stream is given by

$$
\begin{aligned}
& N_{j}=\frac{\dot{m}_{j}}{q_{m_{j}} A_{j}}=\frac{\dot{V}_{j} \rho_{j}}{q_{m_{j}} A_{j}} \quad N_{j} \geq 1 \\
& \sum_{j=1}^{N_{\text {type }}} N_{j}=n \\
& q_{m}=\frac{\dot{m}}{A}=\frac{\rho \dot{V}}{A}=\frac{\rho \cdot u A}{A}=\rho u
\end{aligned}
$$

where $\dot{m}_{j}$ is total mass flow rate for $j$-th type stream in standard state $\left(\mathrm{kg} \cdot \mathrm{s}^{-1}\right) ; q_{m_{j}}$ is the mass flux per unit area $\left(\mathrm{kg} \cdot \mathrm{m}^{-2} \cdot \mathrm{s}^{-1}\right) ; A_{j}$ is section area of each passage which depends on the fin parameters $\left(\mathrm{m}^{2}\right) ; \dot{V}_{j}$ is the total volume flow rate for $j$-th type stream in standard normal state $\left(\mathrm{Nm}^{3} \cdot \mathrm{s}^{-1}\right)$;

The initial total heat load of hot streams $q_{h}$ and cold streams $q_{c}$

$$
\begin{array}{rlrl}
N_{h}=\sum N_{i} & q_{h}=\sum N_{i} \cdot q_{i} & i \in \text { hot stream } \\
N_{c}=\sum N_{j} & q_{c}=\sum N_{j} \cdot q_{j} & j \in \text { cold stream } \\
n & =N_{h}+N_{c} &
\end{array}
$$

The initial mean unbalance of heat load for each passage can be obtained using $q_{h}$ and $q_{c}$

$$
\bar{q}=\frac{1}{n} \sum_{i=1}^{n} q^{(i)}=\frac{q_{h}+q_{c}}{n}
$$

For convenience of calculations of summation Eq.(22),

$$
\begin{array}{cc}
q_{i}>0 & i \in \text { hot stream } \\
q_{j}<0 & j \in \text { cold stream }
\end{array}
$$

The cumulative heat load $\sigma_{q}^{(i)}$ of $i$-th passage can be calculated using recursion:

$$
\begin{aligned}
\sigma_{q^{(i)}} & =\sigma_{q^{(i-1)}}+q^{(i)} \quad i=1, \cdots, n \\
\sigma_{q^{(0)}} & =0
\end{aligned}
$$




$$
\sigma_{q^{(n)}}=q_{h}+q_{c}=\sum_{i=1}^{n} q^{(i)}=n \bar{q}
$$

The passage arrangement means arranging all $N_{j} \times j j \in\left[1, N_{\text {type }}\right]$ streams into $n$ passages to according to the unbiased variance of the cumulative heat load $\sigma_{q}^{(i)}$

$$
\begin{gathered}
\sigma_{\sigma_{q}}=\sqrt{\frac{1}{n-1} \sum_{i=1}^{n}\left(\sigma_{q^{(i)}}-\overline{\sigma_{q}}\right)^{2}} \quad i \in[1, n] \\
\overline{\sigma_{q}}=\frac{1}{n} \sum_{i=1}^{n} \sigma_{q^{(i)}}
\end{gathered}
$$

Single banking means there is no same kinds of streams between the adjacent streams. Multiple banking or hybrid-banking means there exists same kinds of streams between the adjacent streams. The number of $N_{h}, N_{c}$ determines the stacking pattern of passage arrangement

$$
\begin{gathered}
N_{\text {min }}=\min \left(N_{h}, N_{c}\right) \\
N_{\text {max }}=\max \left(N_{h}, N_{c}\right)
\end{gathered}
$$

Passage arrangement is a permutation problem which has numerous arrangements. Passage arrangement can be realized by enumeration method, exclusion method, heuristics method, etc. Recursive Prior Plug-In (RPP) method is proposed to obtain permutation number $P_{\text {total }}$ to overcome the disadvantage of time-consuming and low efficiency.

If $N_{h}=N_{c}$

$$
P_{\text {total }}=2 \cdot A_{N_{h}}^{N_{h}} \cdot A_{N_{c}}^{N_{c}}=2 \cdot N_{h} ! \cdot N_{c} !
$$

If $\left|N_{h}-N_{c}\right|=1$

$$
P_{\text {total }}=N_{h} ! \cdot N_{c} !
$$

If $2 \leq\left|N_{h}-N_{c}\right| \leq N_{\min }+2$ 


$$
P_{\text {total }}=A_{N_{\min }}^{N_{\min }} \cdot A_{N_{\max }}^{N_{\min }+1} \cdot A_{N_{\min }+1}^{N_{\max }-N_{\min }-1}
$$

If $N_{\text {min }}+2 \leq\left|N_{h}-N_{c}\right| \leq 2 N_{\min }+3$

$$
\begin{aligned}
P_{\text {total }}= & A_{N_{\min }}^{N_{\min }} \cdot A_{N_{\max }}^{N_{\min }+1} \cdot A_{N_{\max }-N_{\min }-1}^{N_{\min }+1} \cdot A_{N_{\min }+1}^{N_{\max }-2 N_{\min }-2} \\
& =A_{N_{\min }}^{N_{\min }} \cdot A_{N_{\max }}^{2 N_{\min }+2} \cdot A_{N_{\min }+1}^{N_{\max }-2 N_{\min }-2}
\end{aligned}
$$

$$
\text { If }(s-1) N_{\min }+s \leq\left|N_{h}-N_{c}\right| \leq s N_{\min }+s+1
$$

$$
\begin{gathered}
P_{\text {total }}=A_{N_{\min }}^{N_{\min }} \cdot A_{N_{\max }}^{N_{\min }+1} \cdot A_{N_{\max }-N_{\min }-1}^{N_{\min }+1} \cdot \ldots \cdot A_{N_{\max }-(s-1) N_{\min }-s+1}^{N_{\min }+1} \cdot A_{N_{\min }+1}^{N_{\max }-s N_{\min }-s} \\
=A_{N_{\min }}^{N_{\min }} \cdot A_{N_{\max }}^{s N_{\min }+s} \cdot A_{N_{\min }+1}^{N_{\max }-s N_{\min }-s} \\
s=\operatorname{ceil}\left(\frac{N_{\max }}{N_{\min }+1}\right) \quad s \in Z^{+}
\end{gathered}
$$

The Eq.(36) is the general case with $s+1$ times plug-in when $N_{h} \neq N_{c}$ obtained by mathematical inducting of Eq.(33)-(35). RPP combines two basic types of layer arrangement: single banking with top priority and multiple banking with lower priority.

The effective secondary heat transfer surface $A_{e}$ can be obtained by the fin efficiency $\eta_{f}$. For single banking, the effective heat transfer surface area $A_{e}$ for a passage can be estimated:

$$
\begin{gathered}
A_{e}=A_{1}+\eta_{f, \text { single }} \phi_{f} A_{2} \\
\eta_{f, \text { single }}=\frac{\tanh (\beta)}{\beta} \\
\beta=h_{e} \sqrt{\frac{2 K_{\alpha}}{\lambda_{\mathrm{f}} t_{\mathrm{f}}}}
\end{gathered}
$$

where $K_{\alpha}$ is the effective heat transfer coefficient of a stream $\left(\mathrm{W} \cdot \mathrm{m}^{-2} \cdot \mathrm{K}^{-1}\right) ; \lambda_{\mathrm{f}}$ is the thermal conductivity of fin material $\left(\mathrm{W} \cdot \mathrm{m}^{-1} \cdot \mathrm{K}^{-1}\right) ; h_{e}$ is effective heat transfer distance $(m)$.

For $s$ multiple banking, the parting sheet between the two layers becomes a secondary surface and the fin efficiency $\eta_{f}$ is reduced. The effective heat transfer surface area $A_{e}$ 


$$
\begin{gathered}
A_{e}=\frac{s-1+\eta_{f, \text { multiple }}}{s} A_{1}+\eta_{f, \text { multiple }} A_{2} \quad s \geq 2 \\
\eta_{f, \text { multiple }}=\left(\frac{1}{\beta+\gamma}\right)\left(\frac{B-1}{B+1}\right) \\
\gamma=\frac{\beta}{h_{e}}\left(\frac{1}{d_{f}}-t_{f}\right) \\
B=\left(\frac{1+\gamma}{1-\gamma}\right) e^{2 \beta}
\end{gathered}
$$

\subsection{Multiple Dynamic Equilibrium in plane perpendicular to the flowing}

\section{direction}

There are three modes of heat transfer: conduction, convection, and radiation. In general a body may involve specified heat flux, convection and radiation simultaneously. Thermal efficiency $\varepsilon$ is generally defined as the ratio of real transferred heat quantity and maximum transferred heat quantity.

$$
\begin{aligned}
\varepsilon & =\frac{Q_{\min }}{Q_{\max }} \in(0,1) \\
Q_{\min } & =\min \left(Q_{h},\left|Q_{c}\right|\right) \\
Q_{\max } & =\max \left(Q_{h},\left|Q_{c}\right|\right)
\end{aligned}
$$

If $\varepsilon$ approaches $1, \varepsilon \rightarrow 1$, it means $1-\varepsilon \rightarrow 0$, it can be considered as a thermal equilibrium state with relative thermal equilibrium error $1-\varepsilon$ between hot and cold streams.

The energy balance equation means heat transferred to the body in all modes equals to the heat transferred from the body in all modes. The general form of the heat transfer differential equation in the Cartesian coordinate system using Fourier's law of heat conduction

$$
\begin{gathered}
\rho C_{P} \frac{\partial T}{\partial t}=\nabla(\lambda \nabla T)+\dot{Q} \\
\rho C_{P} \frac{\partial T}{\partial t}=\frac{\partial}{\partial x}\left(\lambda \frac{\partial T}{\partial x}\right)+\frac{\partial}{\partial y}\left(\lambda \frac{\partial T}{\partial y}\right)+\frac{\partial}{\partial z}\left(\lambda \frac{\partial T}{\partial z}\right)+\dot{Q}
\end{gathered}
$$

where $\nabla$ is Laplace operator, $\nabla T=\operatorname{grad} T$; $\rho$ is substance density $\left(\mathrm{kg} \cdot \mathrm{m}^{-3}\right)$; the mass 
specific heat capacity $C_{P}$ at constant pressure $P$ is the amount of energy needed to raise the temperature of $1 \mathrm{~kg}$ of a substance by $1 \mathrm{~K} ; \lambda$ is the thermal conductivity $\left(\mathrm{W} \cdot \mathrm{m}^{-1} \cdot \mathrm{K}^{-1}\right)$.

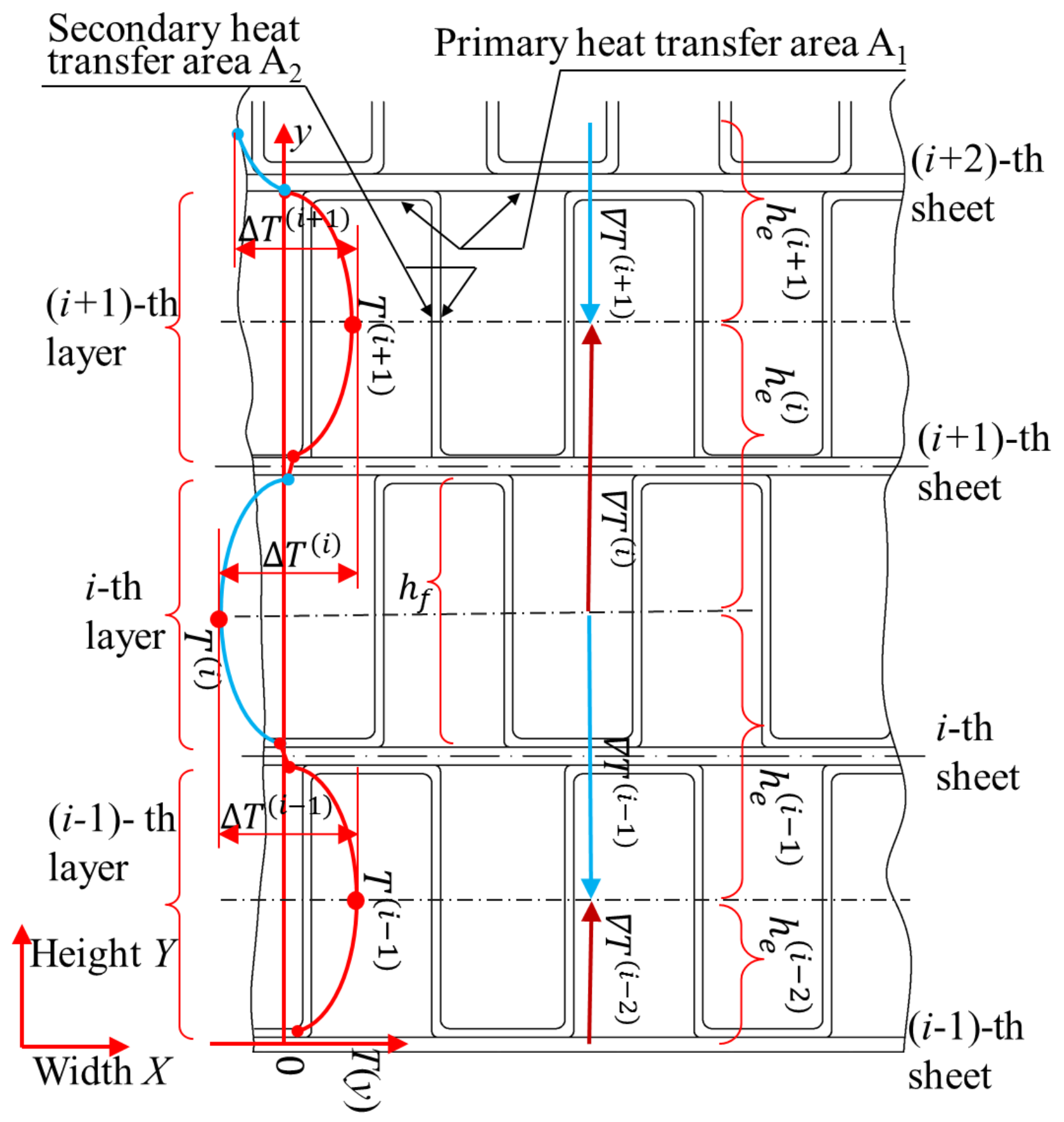

Fig.4. Multiple Dynamic Equilibrium in plane perpendicular to the flowing direction

Temperature gradient $\nabla T$ points to the direction of temperature increase

$$
\nabla T=\lim _{\Delta h \rightarrow 0} \frac{\Delta T}{\Delta h} \vec{h}=\frac{\partial T}{\partial h} \vec{h}
$$


Heat flux $q_{A}\left(\mathrm{~W} \cdot \mathrm{m}^{-2}\right)$

$$
q_{A}=q /_{A}=-\lambda \nabla T
$$

The initial temperature of each section of $i$-th passage stream can be expressed as

$$
T=\left\{T^{(1)}, \cdots, T^{(i)}, \cdots, T^{(n)}\right\} \quad i=1, \cdots, n
$$

The temperature difference $\Delta T^{(i)}$ between the $i$-th passage and the one-sided adjacent $(i+1)$-th streams

$$
\begin{aligned}
\Delta T & =\left\{\Delta T^{(1)}, \cdots, \Delta T^{(i)}, \cdots, \Delta T^{(n-1)}\right\} \\
\Delta T^{(i)} & =T^{(i+1)}-T^{(i)} i=1, \cdots, n-1
\end{aligned}
$$

The large heat transfer area in plane perpendicular to the flowing direction is divided into multiple dynamic equilibriums (MDE) according to the temperature difference sequence.

$$
M D E=\left\{E^{(1)}, \cdots, E^{(i)}, \cdots, E^{(k)}\right\} \quad k \in Z^{+} \& k \leq \frac{n-1}{2}
$$

For the $i$-th equilibrium $E^{(i)}$, the number of streams $N_{E^{(i)}}$ can be determined by thermal equilibrium criterion according to $\Delta T^{(i)}$

$$
\prod_{j=1}^{N_{E^{(i)}}} \Delta T^{(j)}<0 \quad i=1, \cdots, k
$$

The number of streams in each equilibrium,

$$
\begin{gathered}
N_{E}=\left\{N_{E^{(1)}}, \cdots, N_{E^{(i)}}, \cdots, N_{E^{(k)}}\right\} \\
n=\sum_{i=1}^{k} N_{E^{(i)}} \quad N_{E^{(i)}} \geq 2
\end{gathered}
$$

Eq.(58) proves that there exist thermal equilibrium among more than two streams. Therefore, Eq.(58) is available for various stacking patterns of hot and cold streams.

The effective heat transfer distance $h_{e}$ is the Euclidean distance between position $\left.y\right|_{T=\max (|T|)}$ where $T=\max (|T|)$ and the position $\left.y\right|_{\nabla T \rightarrow 0}$ where $\nabla T \rightarrow 0$. Each 
equilibrium state has its corresponding $h_{e}$

$$
\begin{gathered}
h_{e}=\left\{h_{e}{ }^{(1)}, \cdots, h_{e}{ }^{(i)}, \cdots, h_{e}{ }^{(k)}\right\} \\
h_{e}^{(i)}=|y|_{T=\max (|T|)}-\left.y\right|_{\nabla T \rightarrow 0} \mid=N_{E^{(i)} \frac{h_{f}}{2}}
\end{gathered}
$$

Eq.(60) proves that $h_{e}$ will increase when multiple-banking is employed during passage arrangement.

Temperature gradient in $y$ direction of all the streams

$$
\begin{aligned}
& \nabla T=\left\{\nabla T^{(1)}, \cdots, \nabla T^{(i)}, \cdots, \nabla T^{(k)}\right\} \\
& \nabla T^{(i)}=\frac{1}{h_{e}^{(i)}} \int_{0}^{h^{(i)}} \frac{\Delta T}{d y} d y
\end{aligned}
$$

Heat flux of all the ordered streams using Eq.(51)

$$
q_{A}=\left\{q_{A}^{(1)}, \cdots, q_{A}^{(i)}, \cdots, q_{A}^{(k)}\right\}
$$

For each thermal equilibrium, there exist a dynamic thermal equilibrium state. For the $i$-th equilibrium, $i=1, \cdots, k$, using wall conduction thermal, convective thermal, the thermal balance equations can be built

$$
\begin{gathered}
Q_{w}^{(i-1)}+Q_{\alpha}^{(i-1)}=Q_{w}^{(i)}+Q_{\alpha}^{(i)} \quad i=1, \cdots, k \\
Q_{w}^{(i-1)}=q_{A}^{(i-1)} d_{f}^{(i-1)} A_{1}^{(i-1)}=-\lambda_{f}^{(i-1)} \nabla T^{(i-1)} d_{f}^{(i-1)} A_{1}^{(i-1)} \\
Q_{\alpha}^{(i)}=K_{\alpha}^{(i)} A_{2}^{(i)} \Delta T^{(i)}
\end{gathered}
$$

where $K_{\alpha}^{(i)}$ is convective heat transfer coefficient $\left(\mathrm{W} \cdot \mathrm{m}^{-2} \cdot \mathrm{K}^{-1}\right)$.

On the basis of the $k$ equilibriums, the mean temperature $\overline{T_{\text {sheet }}^{(i)}}(i=1, \cdots, n+1)$ of each sheet whose position is $y=(i-1) h_{f}$ can be further obtained. The final equilibrium temperature of each ordered stream in all the passages can be obtained by iterative solving the simultaneous differential equations for all MDE. The temperature inhomogeneity of streams can be obtained by unbiased variance 


$$
\sigma_{T^{(i)}}=\sqrt{\frac{1}{n-1} \sum_{i=1}^{n}\left(T^{(i)}\right)^{2}}
$$

\subsection{Multiple Dynamic Equilibrium of long stream along flowing direction}

Each long stream is also divided into MDE along flowing direction and modelled by energy conservation principle in enthalpy change to obtain the actual phase of stream. For $i$-th equilibrium of each stream, the transferred heat $q^{[i]}$ equals to sensible heat $q_{\text {sensible }}^{[i]}$ and latent heat $q_{\text {latent }}^{[i]}$

$$
\begin{gathered}
q^{[i]}=q_{\text {sensible }}^{[i]}+q_{\text {latent }}^{[i]} \\
q_{\text {sensible }}^{[i]}=\rho^{[i]} A^{[i]} u^{[i]} C_{P}^{[i]} \Delta T^{[i]}=\dot{m}^{[i]} C_{P}^{[i]} \Delta T^{[i]} \\
q_{\text {latent }}^{[i]}=\dot{m}^{[i]} \gamma^{[i]} \quad i=1,2,3, \cdots
\end{gathered}
$$

where $q_{\text {sensible }}^{[i]}$ is sensible heat transfer rate in standard state without phase change (W); $\rho^{[i]}$ is mass density in standard state $\left(\mathrm{kg} \cdot \mathrm{m}^{-3}\right) ; A^{[i]}$ is heat transfer area $\left(\mathrm{m}^{2}\right)$; $u^{[i]}$ is fluid velocity in standard state $\left(\mathrm{m} \cdot \mathrm{s}^{-1}\right) ; C_{P}^{[i]}$ is mass specific heat capacity at constant pressure $\left(\mathrm{J} \cdot \mathrm{kg}^{-1} \cdot \mathrm{K}^{-1}\right) ; \Delta T^{[i]}$ denotes temperature change of $i$-th section( $(\mathrm{K})$; $q_{\text {latent }}^{[i]}$ is latent heat transfer rate with phase change $(\mathrm{W}) ; \dot{m}^{[i]}$ is mass flow rate in standard state $\left(\mathrm{kg} \cdot \mathrm{s}^{-1}\right) ; \gamma^{[i]}$ is latent heat of phase change $\left(\mathrm{J} \cdot \mathrm{kg}^{-1}\right)$.

$q_{\text {latent }}^{[i]}$ is associated with phase change which is greater than $q_{\text {sensible }}^{[i]}$. Temperature change cause phase change and enthalpy drop or rise. Enthalpy $H$ is the total energy a fluid contains including both internal energy and the fluid-mechanical potential energy. When phase changes, heat quantity should be revised as:

$$
Q^{[i]}=\left(q_{\text {sensible }}^{[i]}+q_{\text {latent }}^{[i]}\right) t=\Delta H^{[i]}=m^{[i]} \Delta \dot{H}^{[i]}
$$

where $\Delta H^{[i]}$ is the enthalpy change in the substance $(\mathrm{J}) ; \Delta \dot{H}^{[i]}$ is mass specific enthalpy change $\left(\mathrm{J} \cdot \mathrm{kg}^{-1}\right)$.

The $\Delta \dot{H}$ from $T_{r e f}$ to $T$ can be got by polynomial definite integration 


$$
\Delta \dot{H}^{[i]}(T)=\Delta \dot{H}^{[i]}\left(T_{\text {ref }}\right)+\int_{T_{r e f}}^{T} C_{P}(T) d T
$$

The constant-pressure specific heat $C_{P}$ can be related to the constant-volume specific heat $C_{V}$ which is easy to measure in a calorimeter

$$
C_{P}=\frac{\partial^{2} H}{\partial m \partial T}=\frac{d \dot{H}}{d T}=C_{V}+R
$$

The temperature differences $\Delta T_{\text {end1 }}^{[i]}, \Delta T_{\text {end } 2}^{[i]}$ between two streams at end1 and end2 of $i$-th section can be obtained for various flow configuration such as counterflow, co-current flow, crossflow and cross counterflow. For counterflow, for the two streams at the end 1 and end 2

$$
\begin{aligned}
& \Delta T_{\text {end } 1}^{[i]}=T_{h, o}^{[i]}-T_{c, i}^{[i]} \\
& \Delta T_{\text {end } 2}^{[i]}=T_{h, i}^{[i]}-T_{c, o}^{[i]}
\end{aligned}
$$

When multi-streams undergo phase changes (evaporation or condensation), $\Delta T_{m}^{[i]}$ should be approximated by integral mean temperature difference IMTD

$$
\Delta T_{m}^{[i]}=I M T D^{[i]}=\frac{\left|\int_{0}^{Z^{[i]}} \Delta T d z\right|}{\int_{0}^{Z^{[i]}} d z}=\frac{\left|\int_{0}^{Z^{[i]}}\left(T_{h}^{[i]}(z)-T_{c}^{[i]}(z)\right) d z\right|}{\int_{0}^{Z^{[i]}} d z}=\frac{\sum_{i=1}^{n} A M T D^{[i]}}{n}
$$

For $i$-th sections, the required effective surface area $A_{e, h}^{[i]}, A_{e, c}^{[i]}$ can be obtained from mean temperature difference $\Delta T_{m}^{[i]}$, or from the heat transfer coefficient $K_{\alpha, h}, K_{\alpha, c}$ of hot and cold streams:

$$
K^{[i]} A_{e}^{[i]}=\sum \frac{Q^{[i]}}{\Delta T_{m}^{[i]}}=\frac{\left(\sum K_{\alpha, h}^{[i]} A_{e, h}^{[i]}\right) \cdot\left(\sum K_{\alpha, c}^{[i]} A_{e, c}^{[i]}\right)}{\left.\sum K_{\alpha, h}^{[i]} A_{e, h}^{[i]}+\sum K_{\alpha, c}^{[i]} A_{e, c}^{[i]}\right)} \quad i=1,2,3, \ldots
$$

Where $K^{[i]}$ is heat transfer coefficient of streams in $i$-th sections.

\section{Divide heat transfer process with various Re into MDE for large PFHE}

\subsection{Multiple Dynamic Equilibrium of various working conditions}


For each passage, there exists a dynamic equilibrium, where the heat thermal and cold thermal keep a dynamic equilibrium synchronously. The heat transfer efficiency and pressure drop are two factors which depended and conditioned upon each other in the dynamic equilibrium of the heat transfer process.

The heat transfer factor $j$ ( $j$-factor) of the fin is defined

$$
\begin{gathered}
j=S t \operatorname{Pr}^{2 / 3} \\
S t=\frac{K_{\alpha}}{u \rho C_{P}}=\frac{K_{\alpha}}{q_{m} C_{P}}=\frac{N u}{\operatorname{RePr}} \\
\operatorname{Pr}=\frac{C_{P} \mu}{\lambda} \\
N u=\frac{K_{\alpha} d_{e}}{\lambda}=\frac{q_{A} d_{e}}{\lambda \Delta T}=\frac{q_{A} d_{e}}{\lambda\left(\frac{T_{i}+T_{o}}{2}-\bar{T}_{\text {sheet }}\right)}
\end{gathered}
$$

where $S t$ denotes Stanton number; $P r$ is Prandtl number; $N u$ is Nusselt number; $K_{\alpha}$ is convective heat transfer coefficient $\left(\mathrm{W} \cdot \mathrm{m}^{-2} \cdot \mathrm{K}^{-1}\right)$, denoted respectively as $K_{\alpha, h}, K_{\alpha, c}$ for hot and cold stream; $q_{m}$ is the mass flux per unit area of stream $\left(\mathrm{kg} \cdot \mathrm{m}^{2} \cdot \mathrm{s}^{-1}\right) ; \quad q_{A}$ is heat flux $\left(\mathrm{W} \cdot \mathrm{m}^{-2}\right)$.

Using Eq.(81), the outlet temperature $T_{o}$ can be expressed as

$$
T_{o}=\frac{2 q_{A} d_{e}}{\lambda N_{u}}+2 \bar{T}_{\text {sheet }}-T_{i}
$$

When the $j$ changed into $j^{\prime}$ with ratio $\varepsilon_{j}=\left(j^{\prime}-j\right) / j$,

$$
\frac{\Delta N_{u}}{N_{u}}=\frac{j \varepsilon_{j} R_{e} \times\left(\frac{C_{p} \mu}{\lambda}\right)^{1 / 3}}{j R_{e} \times\left(\frac{C_{p} \mu}{\lambda}\right)^{1 / 3}}=\varepsilon_{j}
$$

The changed outlet temperature $T_{o}^{\prime}$ of the stream can be obtained

$$
\begin{gathered}
T_{o}^{\prime}=\frac{2 q_{A} d_{e}}{\lambda N_{u}\left(1+\varepsilon_{j}\right)}+2 \bar{T}_{\text {sheet }}-T_{i}=\frac{T_{o}+T_{i}-2 \bar{T}_{\text {sheet }}}{1+\varepsilon_{j}}+2 \bar{T}_{\text {sheet }}-T_{i} \\
=\frac{T_{o}+2 \varepsilon_{j} \bar{T}_{\text {sheet }}-\varepsilon_{j} T_{i}}{1+\varepsilon_{j}}
\end{gathered}
$$

The change ratio of outlet temperature $T_{o}$ of the stream can be obtained 
$\frac{\Delta T_{o}}{T_{o}}=\frac{T_{o}^{\prime}-T_{o}}{T_{o}}=\frac{\frac{2 q_{A} d_{e}}{\lambda N_{u}}\left(\frac{-\varepsilon_{j}}{1+\varepsilon_{j}}\right)}{T_{o}}=\frac{T_{o}+T_{i}-2 \bar{T}_{\text {sheet }}}{T_{o}}\left(\frac{-\varepsilon_{j}}{1+\varepsilon_{j}}\right)=\left(\frac{2 \bar{T}_{\text {sheet }}-T_{i}}{T_{o}}-1\right)\left(\frac{\varepsilon_{j}}{1+\varepsilon_{j}}\right)$

The change ratio of outlet temperature $T_{o}$ can be expressed by piecewise function according to the $\varepsilon_{j}$ :

$$
\begin{aligned}
& \varepsilon_{j} \in(0,+\infty) \quad \frac{\Delta T_{o}}{T_{o}} \in\left[\left(\frac{2 \bar{T}_{\text {sheet }}-T_{i}}{T_{o, \text { max }}}-1\right)\left(\frac{\varepsilon_{j}}{1+\varepsilon_{j}}\right),\left(\frac{2 \bar{T}_{\text {sheet }}-T_{i}}{T_{o, \text { min }}}-1\right)\left(\frac{\varepsilon_{j}}{1+\varepsilon_{j}}\right)\right] \\
& \varepsilon_{j} \in(-1,0) \quad \frac{\Delta T_{o}}{T_{o}} \in\left[\left(\frac{2 \bar{T}_{\text {sheet }}-T_{i}}{T_{o, \text { min }}}-1\right)\left(\frac{\varepsilon_{j}}{1+\varepsilon_{j}}\right),\left(\frac{2 \bar{T}_{\text {sheet }}-T_{i}}{T_{o, \text { max }}}-1\right)\left(\frac{\varepsilon_{j}}{1+\varepsilon_{j}}\right)\right]
\end{aligned}
$$

The fanning friction factor $f$ ( $f$-factor) can be defined by the frictional pressure loss $\Delta P$ across a plate-fin passage and at any associated entry, exit for single-phase stream

$$
f=\Delta P \frac{d_{e}}{2 L \rho u^{2}}=\Delta P \frac{\rho d_{e}}{2 L q_{m}^{2}}=\Delta P \frac{d_{e}^{2}}{2 L R e \mu u}
$$

Where $\Delta P$ is pressure drop $(\mathrm{Pa}) ; L$ is the passage length $(\mathrm{m})$.

Using Eq.(88), the pressure drop $\Delta P$ can be expressed as

$$
\Delta P=\frac{2 f L q_{m}^{2}}{\rho d_{e}}
$$

When the $f$ changed with ratio $\varepsilon_{f}=\left(f^{\prime}-f\right) / f$, the changed pressure drop $\Delta P^{\prime}$ of the stream can be obtained

$$
\Delta P^{\prime}=\frac{2 f L q_{m}^{2}}{\rho d_{e}}\left(1+\varepsilon_{f}\right)
$$

The changed ratio of pressure drop $\Delta P$ of the stream can be obtained

$$
\frac{\Delta(\Delta P)}{\Delta P}=\frac{\Delta P^{\prime}-\Delta P}{\Delta P}=\frac{\frac{2 f L q_{m}^{2} \varepsilon_{f}}{\rho d_{e}}}{\frac{2 f L q_{m}^{2}}{\rho d_{e}}}=\varepsilon_{f}
$$

From Eq.(84) and Eq.(90), improving the $j$-factor generally improves the $f$-factor. Therefore, the heat transfer factor and friction factor are regarded as two inter-constraint measures.

$$
\varepsilon_{j} \cdot \varepsilon_{f} \leq 0 \quad \varepsilon_{j}, \varepsilon_{f} \in(-1,1)
$$


The equilibrium degree between two inter-constraint measures can characterize the equilibrium between heat transfer factor and friction factor. Therefore, the heat transfer process can be pre-divided into MDE according to the dynamic equilibriums between two inter-constraint measures using the value of $\frac{d j}{d f}$. The interval integral of

$\frac{d j}{d f}$ can be used to improve the MDE by iteration. Renault number of multi-streams fluctuates in wide range which generates various working conditions. The MDE help to determine the optimal fins under various working conditions.

\subsection{Validation and Verification of the Multiple Dynamic Equilibrium}

Using cryogenic ASU process, the multi-streams: $N_{\text {type }}=6$. The cold streams B, C, D, F are oxygen gas $\left(\mathrm{O}_{2}\right)$, nitrogen gas $\left(\mathrm{N}_{2}\right)$, wasted $\mathrm{N}_{2}$, pressure $\mathrm{N}_{2}$. The hot streams A, E are Air, pressure air. The total mass flow rate $\dot{m}$ of A, B, C, D, E, F stream is respectively $11.26 \mathrm{~kg} \cdot \mathrm{s}^{-1}, 3.56 \mathrm{~kg} \cdot \mathrm{s}^{-1}, 10.27 \mathrm{~kg} \cdot \mathrm{s}^{-1}, 9.93 \mathrm{~kg} \cdot \mathrm{s}^{-1}, 4.78 \mathrm{~kg} \cdot \mathrm{s}^{-1}$, $6.58 \mathrm{~kg} \cdot \mathrm{s}^{-1}$. The heat load $q_{A}: q_{B}: q_{C}: q_{D}: q_{E}: q_{F}=1.4165:-1:-1.0635:-1.0522$ : 1.2976:-0.8100. 


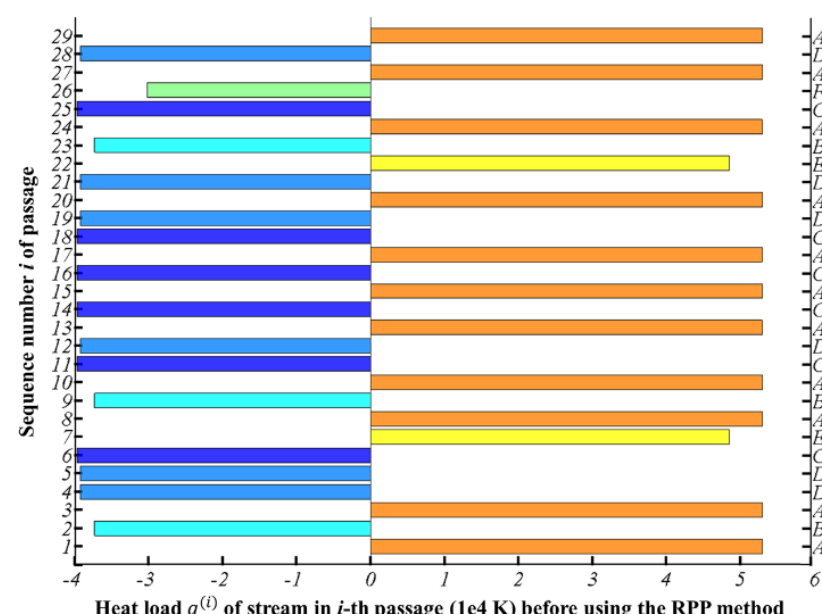

(a)

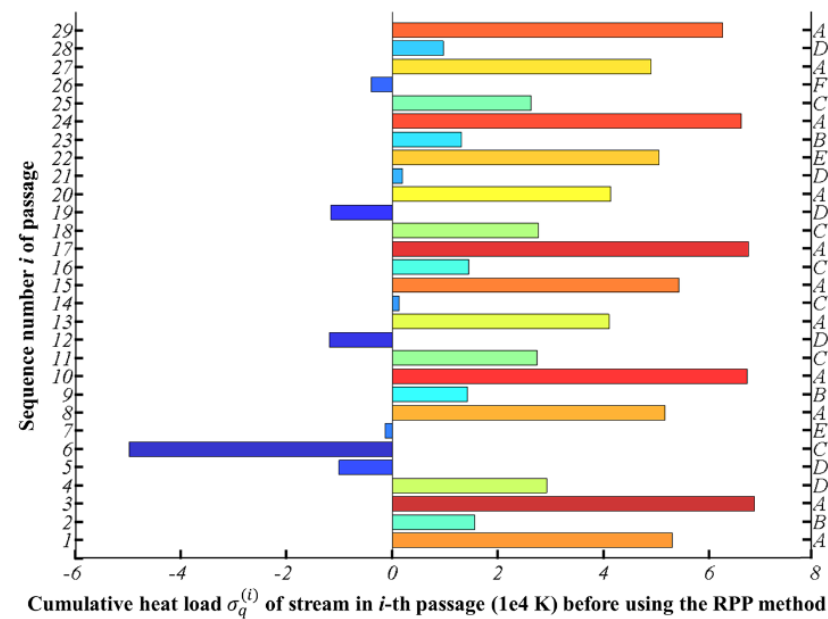

(c)

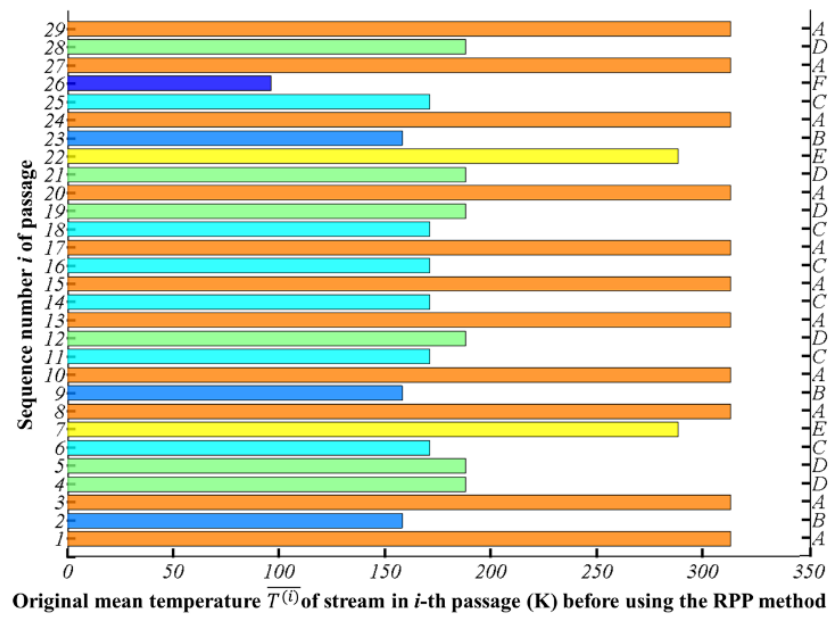

(e)

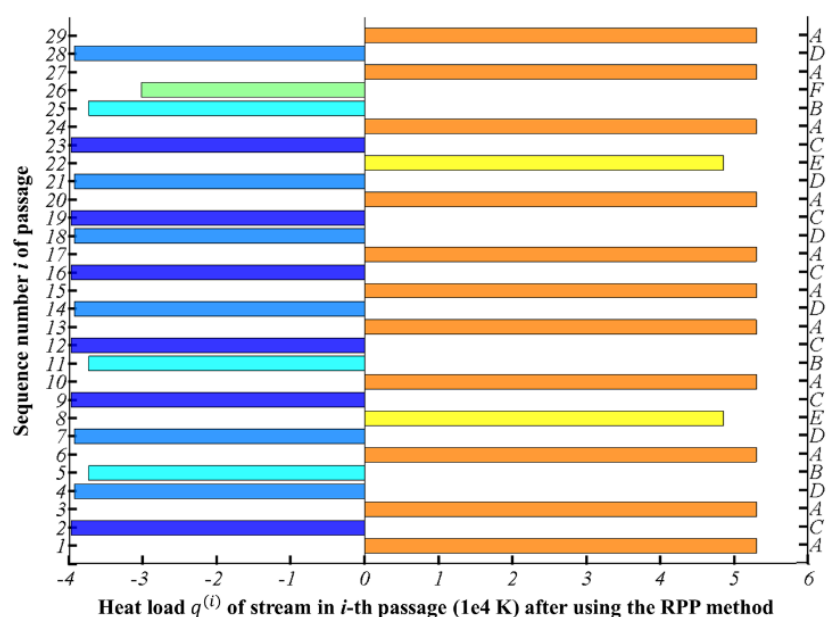

(b)

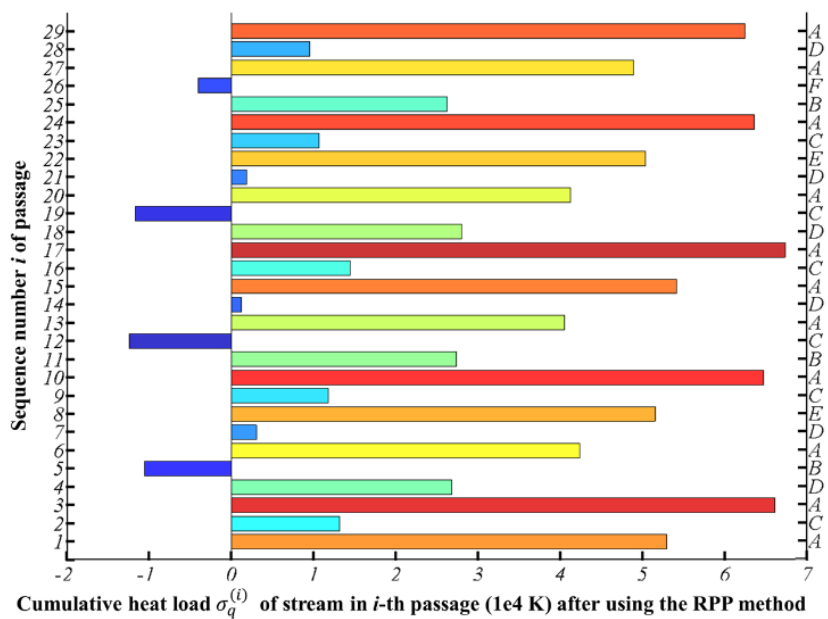

(d)

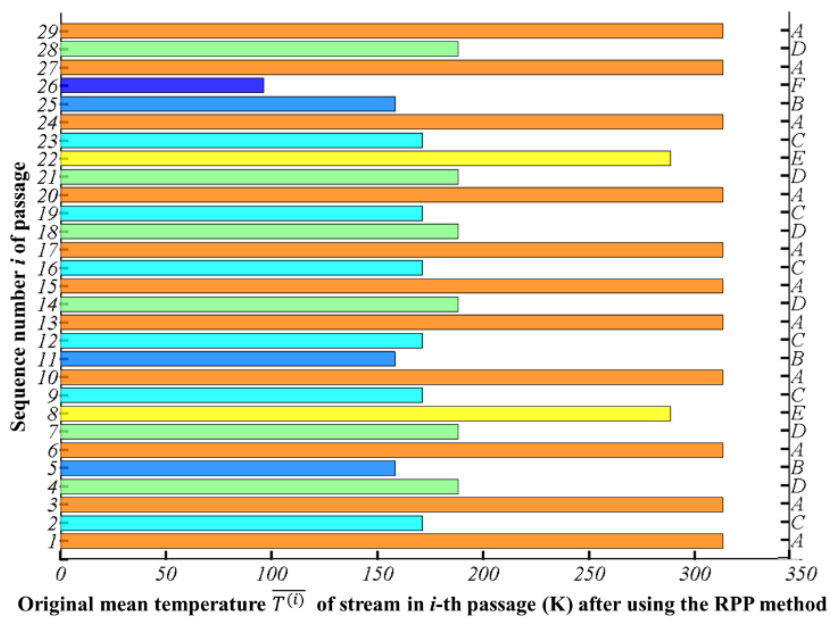

(f)

Fig.5. Heat load $q^{(i)}$, cumulative heat load $\sigma_{q}^{(i)}$ and mean temperature $\overline{T^{(l)}}$ of stream in $i$-th passage, where (a)(c)(e) are about the passage arrangement without using RPP method, (b)(d)(f) are about the passage arrangement using the proposed RPP method.

In Fig.5(a), there exists three-banking among 4,5,6 layers. In Fig.5(b), the passage 
arrangement is improved by using RPP method. In Fig.(c), all layers are divided into 22 MDE using Eq.(56), $N_{E}=\{2,2,3,4,2,2,3,2,2,2,2,2,3,2,2,2,2,2,3,2,2,2\}$, in Fig.(d), all layers are divided into 24 MDE, $N_{E}=\{2,2,3,2,2,2,2,2,2,3,2,2,2,2,3,2,2,2,2,2,3,2,2,2\}$. In Fig5.(e), unbiased variance of each stream $\sigma_{T^{(i)}}=72.5299$, unbiased variance of temperature difference $\sigma_{\Delta T^{(i)}}=125.6709$. In Fig5.(f), unbiased variance of each stream $\sigma_{T^{(i)}}=72.5299$, unbiased variance of temperature difference $\sigma_{\Delta T^{(i)}}=130.2573$. 


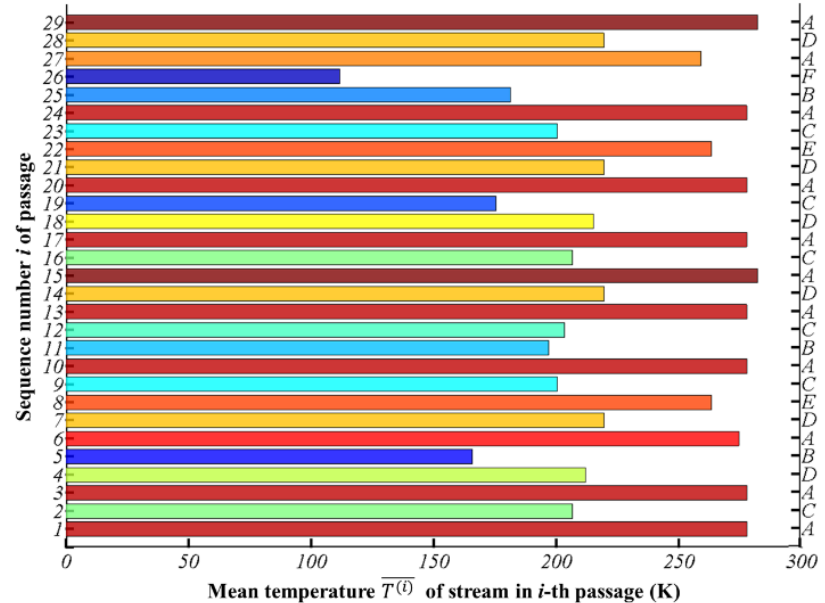

(a)

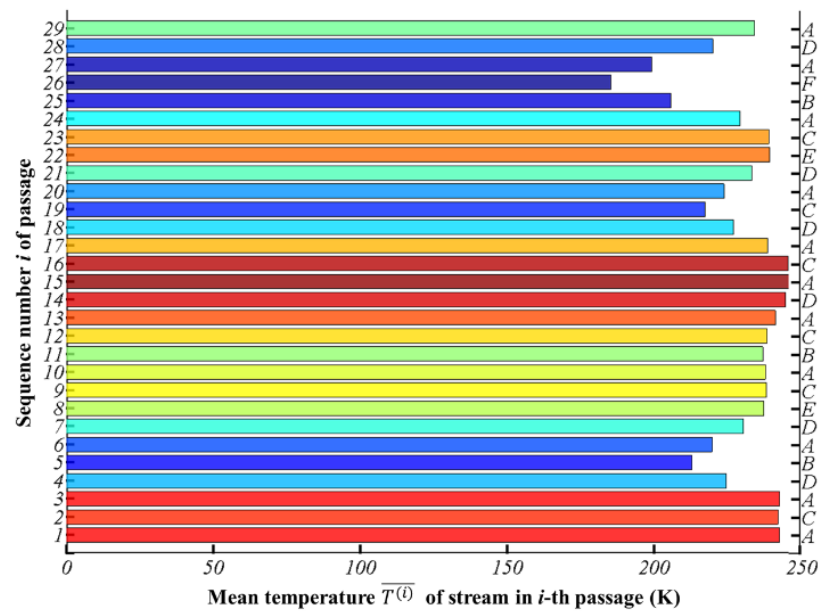

(c)

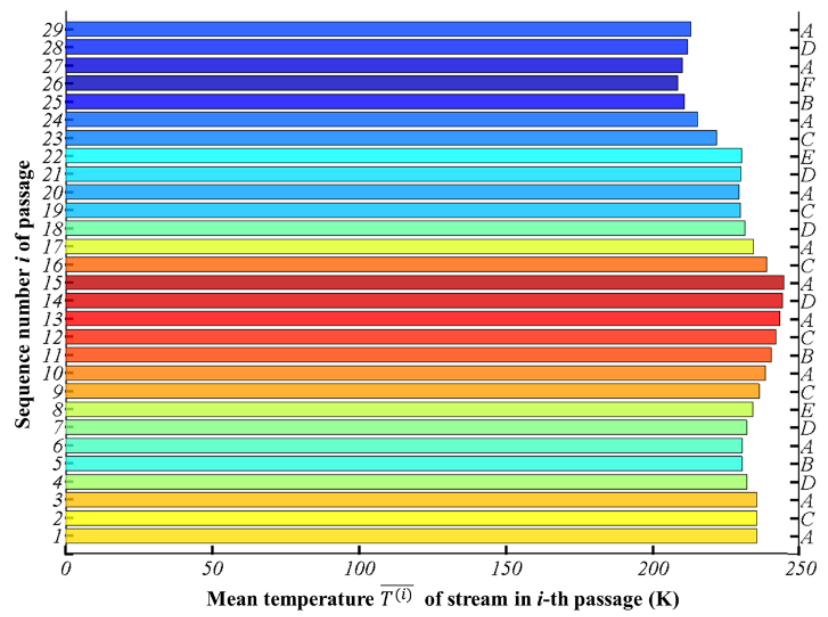

(e)

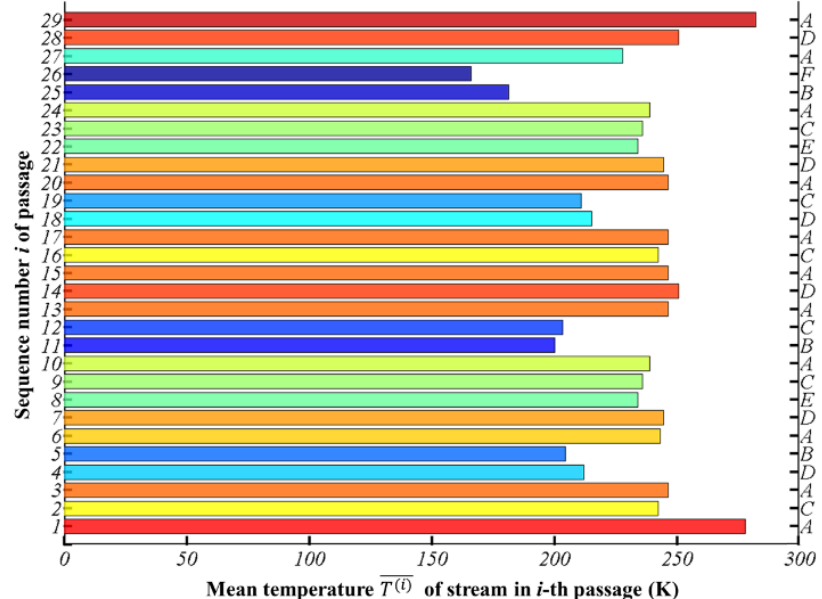

(b)

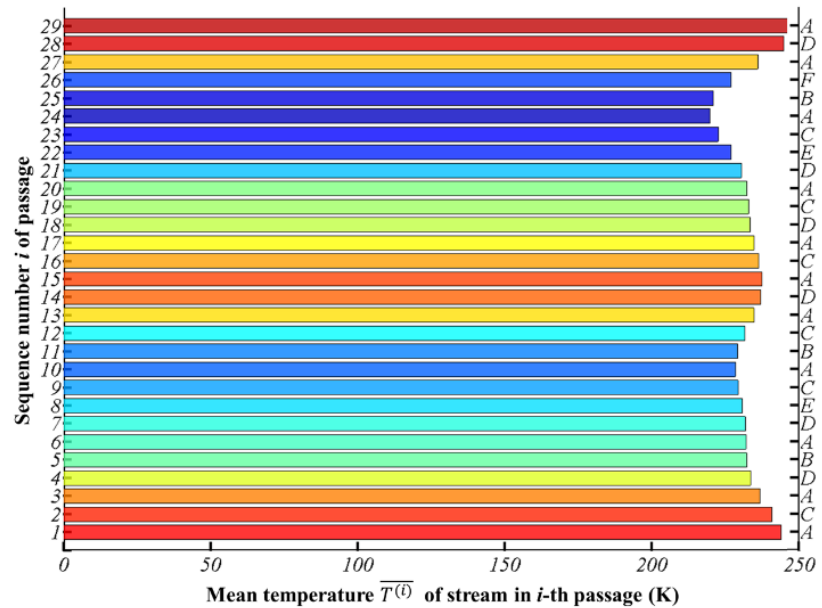

(d)

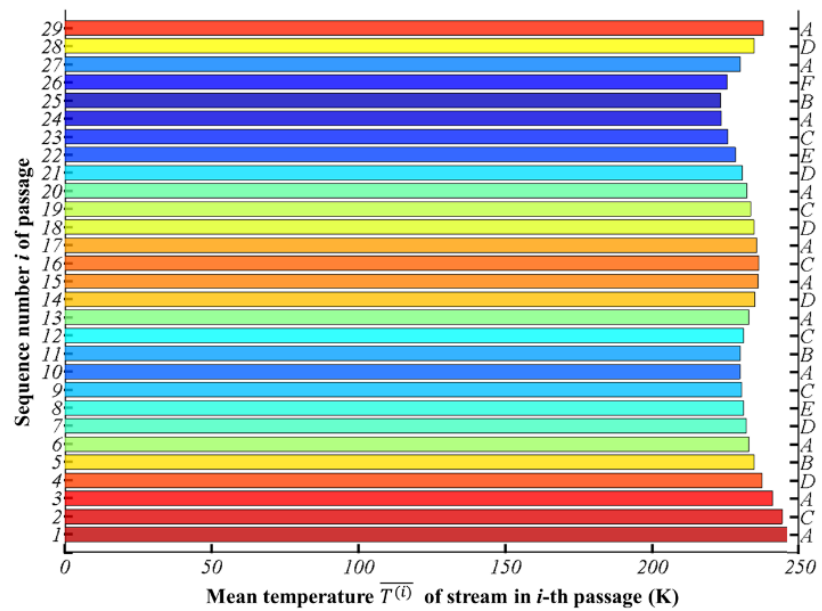

(f)

Fig.6. Mean temperature $\overline{T^{(l)}}$ of stream in $i$-th passage before and after using MDE method, where (a) (c) (e) are about before using MDE method under low, moderate and full working conditions ; (b) (d) (f) are about after using MDE method under low, moderate and full working conditions.

The original temperature of Fig.6 is shown in Fig.5(f). In Fig6.(a), unbiased 
variance of each stream $\sigma_{T}=37.1914 \mathrm{~K}$. In Fig5.(b), unbiased variance of each stream $\sigma_{T}=25.1633 \mathrm{~K}$. Passage temperature inhomogeneity is decreased from 37.1914 to 25.1633 K with ratio of $-32.34 \%$ using Eq.(67). From Fig5.(c)(d), passage temperature inhomogeneity is decreased from $12.1447 \mathrm{~K}$ to $8.4561 \mathrm{~K}$ with ratio of $-30.37 \%$. From Fig5.(e)(f), passage temperature inhomogeneity is decreased from $9.5889 \mathrm{~K}$ to 6.7512 $\mathrm{K}$ with ratio of $-29.59 \%$. After using MDE method, the temperature differences $\Delta T_{\text {end } 1}, \Delta T_{\text {end } 2}$ between two streams at end 1 and end 2 are also reduced, which improves the heat transfer coefficient of large PFHE using Eq.(77).

\section{Heat transfer experiment under various working conditions}

\subsection{Experimental schematic of heat transfer for different types of fins}

The heat transfer experiment is about different types of cores and fins under various working conditions shown in Fig.7. In physical experiment, temperature accuracy is $0.1 \mathrm{~K}$, differential pressure accuracy is $1 \mathrm{~Pa}$, volumetric flux accuracy is $0.1 \mathrm{ml}$. An atmospheric pressure (atm) is $0.1013 \mathrm{Mpa}$. Actual pressure is the sum of gage pressure and atm, which is automatically controlled by the electromagnetic solenoid valve. The outlet temperature of multi streams can be obtained by thermocouple sensors placed in $X O Y$ plane. When $\varepsilon \rightarrow 1$ using Eq.(45), it can be considered as dynamic equilibrium between hot streams and cold streams. 


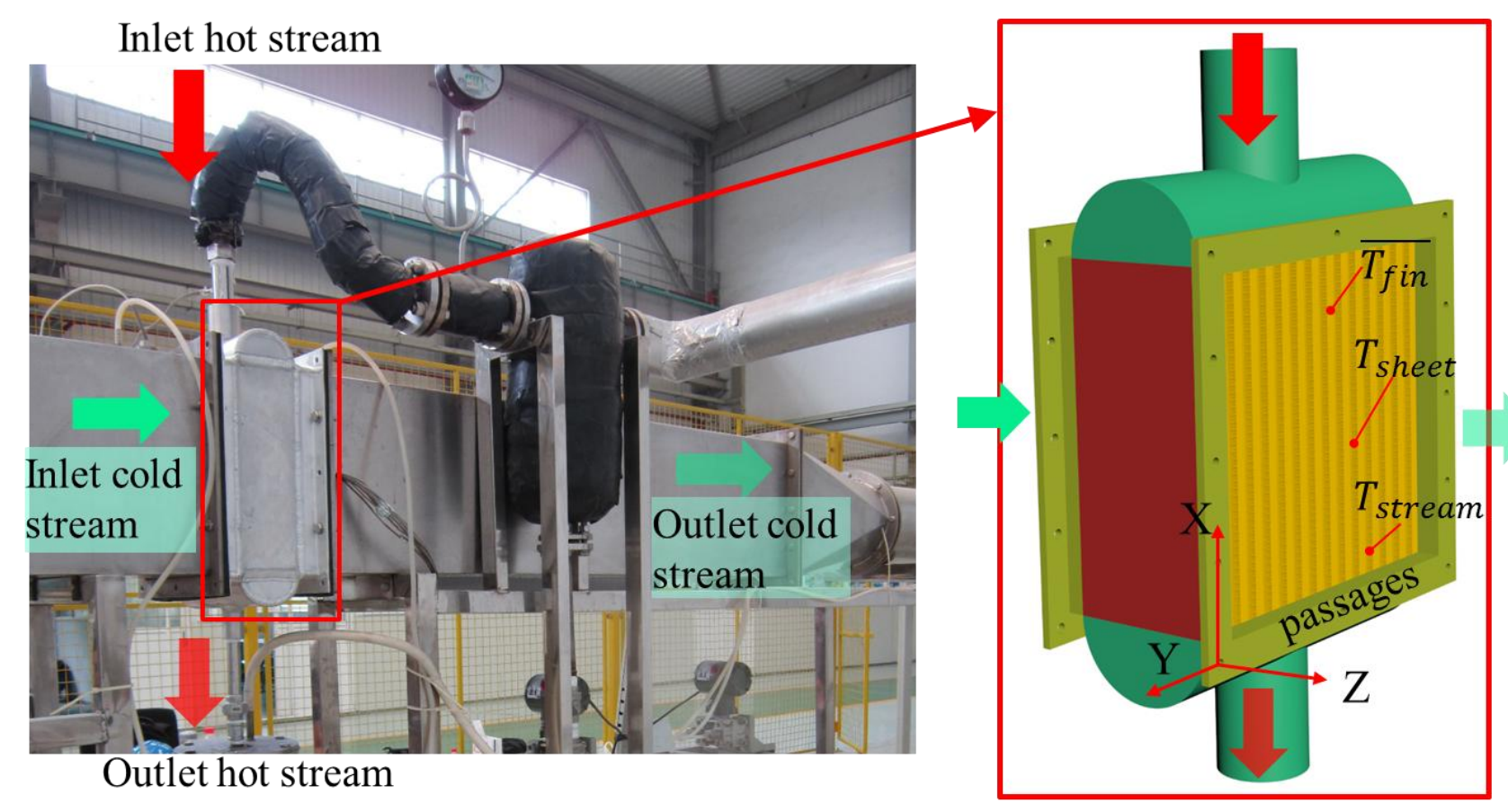

Fig.7. Experiment of heat transfer of different streams in the passages

The parameters of three kinds six types of fins are shown in Table 1.

Table 1 The parameters of three kinds six types of cores and fins

\begin{tabular}{|c|c|c|c|c|c|c|c|c|}
\hline \multicolumn{2}{|c|}{ Fin parameters } & $h_{\mathrm{f}}(\mathrm{mm})$ & $t_{\mathrm{f}}(\mathrm{mm})$ & $p_{\mathrm{f}}(\mathrm{mm})$ & $d_{\mathrm{e}}(\mathrm{mm})$ & $A\left(\mathrm{~m}^{2}\right)$ & $\mathrm{A}_{1}+\mathrm{A}_{2}\left(\mathrm{~m}^{2}\right)$ & $\mathrm{A}_{2} /\left(\mathrm{A}_{1}+\mathrm{A}_{2}\right)$ \\
\hline \multirow{4}{*}{ Kind1 } & Type1 & 3.98 & 0.51 & 4.21 & 3.5813 & $3.0496 \mathrm{e}-3$ & 3.4062 & 0.4840 \\
\cline { 2 - 9 } & Type2 & 4.65 & 0.42 & 3.86 & 3.7943 & $3.7697 \mathrm{e}-3$ & 3.9741 & 0.5515 \\
\cline { 2 - 9 } & Ratio $\varepsilon$ & $16.83 \%$ & $-17.65 \%$ & $-8.31 \%$ & $5.95 \%$ & $23.61 \%$ & $16.67 \%$ & $13.96 \%$ \\
\hline \multirow{4}{*}{ Kind2 } & Type3 & 5.98 & 0.39 & 2.82 & 3.3875 & $4.8169 \mathrm{e}-3$ & 5.6879 & 0.6970 \\
\cline { 2 - 9 } & Type4 & 6.72 & 0.35 & 2.67 & 3.4012 & $5.5350 \mathrm{e}-3$ & 6.5094 & 0.7330 \\
\cline { 2 - 9 } & Ratio $\varepsilon$ & $12.37 \%$ & $-10.26 \%$ & $-5.32 \%$ & $0.41 \%$ & $14.91 \%$ & $14.44 \%$ & $5.17 \%$ \\
\hline \multirow{3}{*}{ Kind3 } & Type5 & 7.58 & 0.36 & 2.23 & 2.9706 & $6.0544 \mathrm{e}-3$ & 8.1525 & 0.7943 \\
\cline { 2 - 9 } & Type6 & 8.51 & 0.29 & 2.14 & 3.0203 & $7.1061 \mathrm{e}-3$ & 9.4112 & 0.8163 \\
\cline { 2 - 9 } & Ratio $\varepsilon$ & $12.27 \%$ & $-19.44 \%$ & $-4.04 \%$ & $1.67 \%$ & $17.37 \%$ & $15.44 \%$ & $2.77 \%$ \\
\hline
\end{tabular}

\subsection{Experimental results under variable working conditions}

Using Eq. (78) and Eq. (88), the heat transfer factor (j-factor) and friction factor ( $f$-factor) of the three kinds six types of fins are computed real-timely in experiment. 
The heat transfer factor, friction factor, mean outlet temperature and pressure drop of six types of fins under three working conditions are shown in Fig.8.
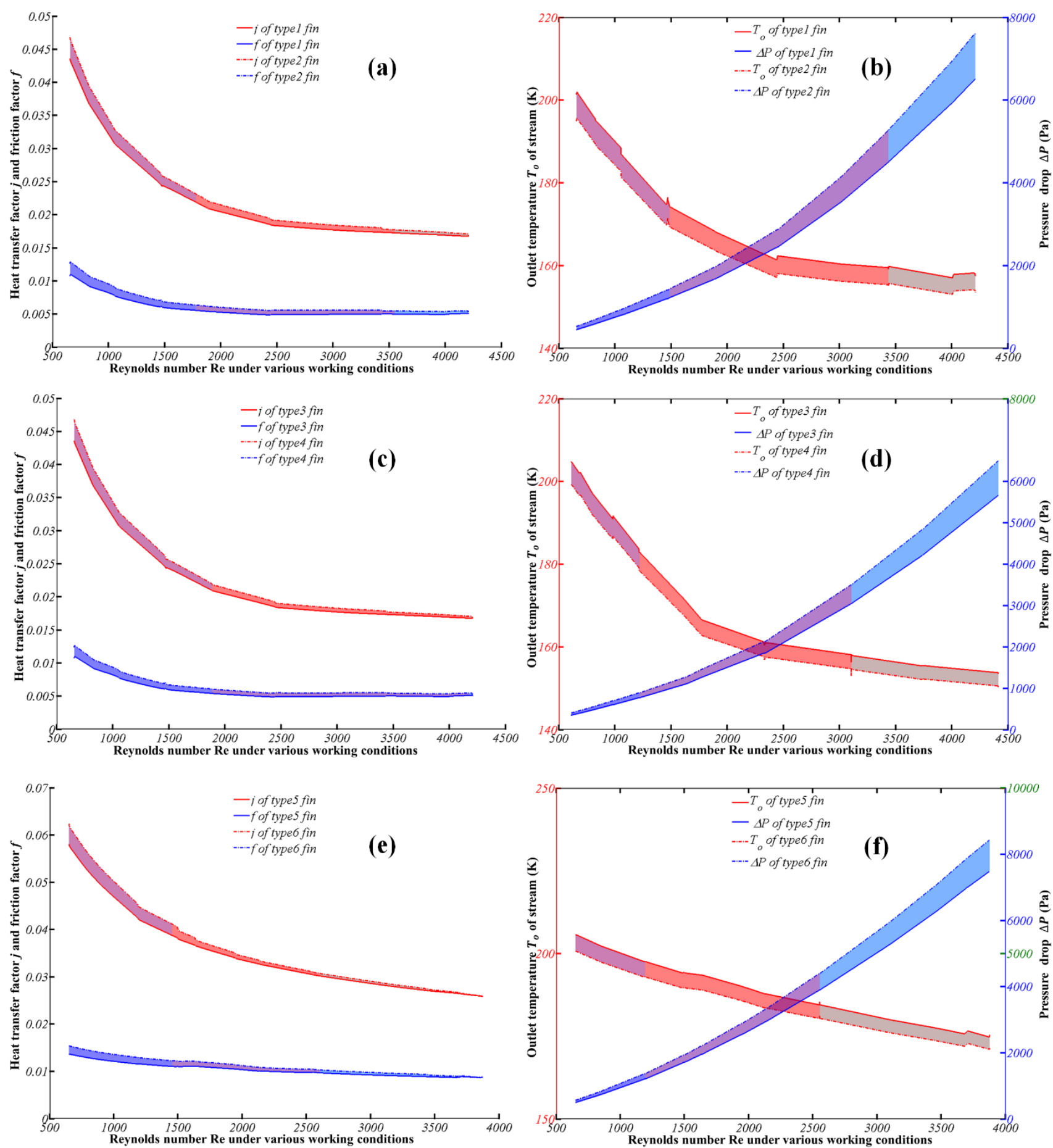

Fig.8. The heat transfer factor, friction factor, mean outlet temperature and pressure drop of six types of fins under three working conditions where (a) is about Type1; (b) is about Type2; (c) is about Type3; (d) is about Type4; (e) is about Type5; (f) is about Type6.

The mean outlet temperature and pressure drop of different fins under three working conditions are shown in Table 2. 
Table 2 The outlet temperature and pressure drop of different fins

\begin{tabular}{|c|c|c|c|c|c|c|c|}
\hline \multirow{2}{*}{\multicolumn{2}{|c|}{ Parameters }} & \multicolumn{3}{|c|}{ Mean outlet temperature $\overline{T_{o}}(\mathrm{~K})$} & \multicolumn{3}{|c|}{ Mean pressure drop $\overline{\Delta P}(\mathrm{~Pa})$} \\
\hline & & Working & Working & Working & Working & Working & Working \\
\hline \multirow{4}{*}{ Kind 1} & $\operatorname{Re}$ & {$[656,1486]$} & {$[1486,3433]$} & {$[3433,4207]$} & {$[656,1486]$} & {$[1486,3433]$} & {$[3433,4207]$} \\
\hline & Type1 & 186.7119 & 162.5515 & 158.0263 & 880.4486 & 3265.7732 & 6235.1779 \\
\hline & Type2 & 181.1402 & 158.2676 & 154.0037 & 1021.1443 & 3828.4982 & 7356.8864 \\
\hline & Ratio $\varepsilon$ & $-2.98 \%$ & $-2.64 \%$ & $-2.55 \%$ & $15.98 \%$ & $17.23 \%$ & $17.99 \%$ \\
\hline \multirow{4}{*}{ Kind 2} & $\operatorname{Re}$ & {$[610,1221]$} & {$[1221,3105]$} & {$[3105,4409]$} & {$[610,1221]$} & {$[1221,3105]$} & {$[3105,4409]$} \\
\hline & Type3 & 194.3485 & 161.9545 & 154.7929 & 557.6148 & 2271.554 & 4866.9071 \\
\hline & Type4 & 189.3140 & 158.3833 & 151.5717 & 636.6846 & 2591.6161 & 5579.4223 \\
\hline & Ratio $\varepsilon$ & $-2.59 \%$ & $-2.21 \%$ & $-2.08 \%$ & $14.18 \%$ & $14.09 \%$ & $14.64 \%$ \\
\hline \multirow{4}{*}{ Kind3 } & $\mathrm{Re}$ & {$[651,1193]$} & {$[1193,2552]$} & {$[2552,3873]$} & {$[651,1193]$} & {$[1193,2552]$} & {$[2552,3873]$} \\
\hline & Type5 & 201.7294 & 191.1424 & 177.6385 & 845.8369 & 2370.8716 & 6312.0556 \\
\hline & Туре6 & 196.8891 & 187.1284 & 173.8211 & 958.5013 & 2704.2162 & 7193.8498 \\
\hline & Ratio $\varepsilon$ & $-2.40 \%$ & $-2.10 \%$ & $-2.15 \%$ & $13.32 \%$ & $14.06 \%$ & $13.97 \%$ \\
\hline
\end{tabular}

From Table 2, under working condition for kind1 fins, from type1 to type2, the mean outlet temperature $\bar{T}_{o}$ decreases by the ratio of $-2.98 \%,-2.64 \%,-2.55 \%$ and the pressure drop $\overline{\Delta P}$ increases by the ratio of $15.98 \%, 17.23 \%, 17.99 \%$. Under working condition for kind 2 fins, from type 3 to type 4 , the $\overline{T_{o}}$ decreases by the ratio of $-2.59 \%,-2.21 \%,-2.08 \%$ and the $\overline{\Delta P}$ increases by the ratio of $14.18 \%, 14.09 \%$, 14.64\%. Under working condition for kind3 fins, from type5 to type6, the $\bar{T}_{o}$ decreases by the ratio of $-2.40 \%,-2.10 \%,-2.15 \%$ and the $\overline{\Delta P}$ increases by the ratio of $13.32 \%, 14.06 \%, 13.97 \%$.

According to Eq.(92), under working condition1, the value of $\left|\varepsilon_{\overline{T_{O}}}\right| / \varepsilon_{\overline{\Delta P}}$ for each kind is $0.1865,0.1827,0.1802$, therefore, the preferable fin is kind1>kind2>kind3 
Under working condition2, the value of $\left|\varepsilon_{\overline{T_{o}}}\right| / \varepsilon_{\overline{\Delta P}}$ is $0.1532,0.1568,0.1494$, therefore, the preferable fin is kind2> kind1>kind3. Under working condition3, the value of $\left|\varepsilon_{\overline{T_{o}}}\right| / \varepsilon_{\overline{\Delta P}}$ is $0.1417,0.1421,0.1539$ in therefore, the preferable fin is kind3>kind2>kind1. Based on the experimental results, the fin type can be determined in thermal design.

The outlet temperature of streams in different passages under variable working conditions is shown in Fig.9. 

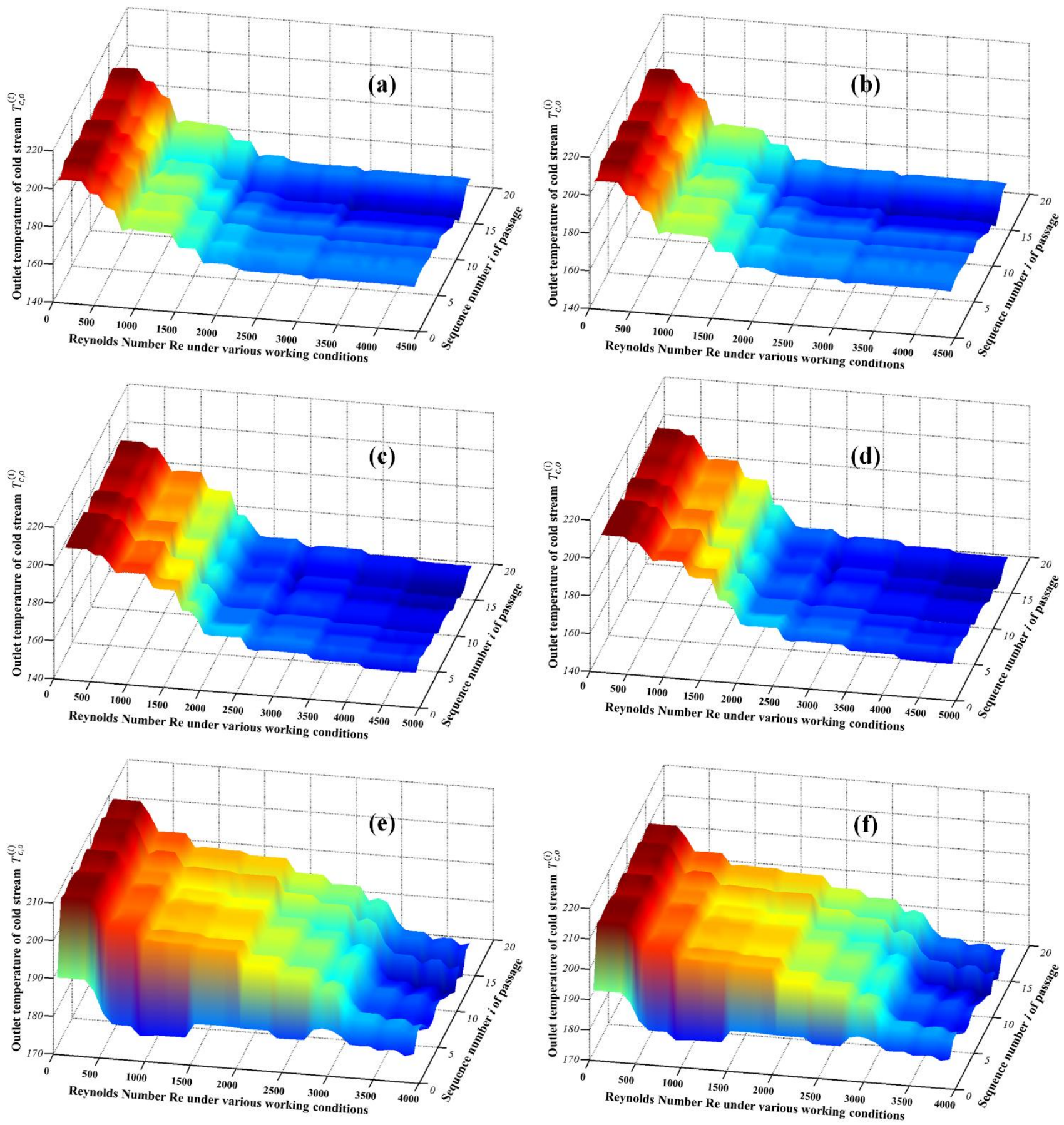

Fig.9. Outlet temperature of streams in different passages under variable working conditions where (a) is about Type1; (b) is about Type2; (c) is about Type3; (d) is about Type4; (e) is about Type5; (f) is about Type6.

In Fig.9(a), the mean unbiased variance of the temperature $\operatorname{mean}\left(\sigma_{T_{o}}\right)=3.0411 \mathrm{~K}$, the maximum unbiased variance of the temperature $\max \left(\sigma_{T_{o}}\right)=3.8237 \mathrm{~K}$ at $\operatorname{Re}=$ 4001, the minimum unbiased variance of the temperature $\min \left(\sigma_{T_{o}}\right)=1.6967 \mathrm{~K}$ at Re=658. In Fig.9(b), mean $\left(\sigma_{T_{o}}\right)=3.1664 \mathrm{~K}, \max \left(\sigma_{T_{o}}\right)=3.9810 \mathrm{~K}$ at $\mathrm{Re}=4003$, 
$\min \left(\sigma_{T_{o}}\right)=1.7671 \mathrm{~K}$ at $\operatorname{Re}=660 . \quad$ In Fig.9(c), $\operatorname{mean}\left(\sigma_{T_{o}}\right)=2.5842 \mathrm{~K}$, $\max \left(\sigma_{T_{o}}\right)=4.1082 \mathrm{~K}$ at $\mathrm{Re}=1773, \min \left(\sigma_{T_{o}}\right)=1.4104 \mathrm{~K}$ at $\mathrm{Re}=612$. In Fig.9(d), $\operatorname{mean}\left(\sigma_{T_{o}}\right)=2.6905 \mathrm{~K}, \max \left(\sigma_{T_{o}}\right)=4.2778 \mathrm{~K}$ at $\mathrm{Re}=1775, \min \left(\sigma_{T_{o}}\right)=1.4690 \mathrm{~K}$ at Re=619. In Fig.9(e), mean $\left(\sigma_{T_{o}}\right)=3.8567 \mathrm{~K}, \max \left(\sigma_{T_{o}}\right)=5.6160 \mathrm{~K}$ at $\mathrm{Re}=1192$, $\min \left(\sigma_{T_{o}}\right)=2.3836 \mathrm{~K}$ at $\mathrm{Re}=2552$. In Fig.9(f), $\operatorname{mean}\left(\sigma_{T_{o}}\right)=4.0152 \mathrm{~K}, \max \left(\sigma_{T_{o}}\right)=$ $5.6160 \mathrm{~K}$ at $\mathrm{Re}=1198, \min \left(\sigma_{T_{o}}\right)=2.4809 \mathrm{~K}$ at $\mathrm{Re}=2559$.

Comparisons on outlet temperature between MDE method and other methods are shown in Table 3. It proves that the more accurate outlet temperature can be obtained by using the MDE method.

Table 3 Comparisons on outlet temperature between MDE method and other methods

\begin{tabular}{|c|c|c|c|c|c|c|c|}
\hline \multirow{2}{*}{ Outlet Temperature $(\mathrm{K})$} & \multicolumn{2}{c|}{ Kind1 } & \multicolumn{2}{c|}{ Kind2 } & \multicolumn{2}{c|}{ Kind3 } \\
\cline { 2 - 8 } & Type1 & Type2 & Type3 & Type4 & Type5 & Type6 \\
\hline \multirow{3}{*}{\begin{tabular}{c} 
Experimental Results \\
\cline { 2 - 8 }
\end{tabular}} & $\max \left(\sigma_{T_{o}}\right)$ & 3.0411 & 3.1664 & 2.5842 & 2.6905 & 3.8567 & 4.0152 \\
\cline { 2 - 8 } & $\min \left(\sigma_{T_{o}}\right)$ & 1.6967 & 1.7671 & 1.4104 & 1.4690 & 2.3836 & 2.4809 \\
\hline \multirow{3}{*}{$\begin{array}{c}\text { Before using MDE } \\
\text { method }\end{array}$} & $\operatorname{mean}\left(\sigma_{T_{o}}\right)$ & 3.0499 & 3.1752 & 2.5916 & 2.6985 & 3.8422 & 4.0345 \\
\cline { 2 - 8 } & $\max \left(\sigma_{T_{o}}\right)$ & 3.8353 & 3.9644 & 4.1213 & 4.2642 & 5.6339 & 5.6510 \\
\cline { 2 - 8 } & $\min \left(\sigma_{T_{o}}\right)$ & 1.6879 & 1.7775 & 1.4022 & 1.4777 & 2.3977 & 2.4956 \\
\hline \multirow{3}{*}{$\begin{array}{c}\text { After using MDE } \\
\text { method }\end{array}$} & $\operatorname{mean}\left(\sigma_{T_{o}}\right)$ & 3.0396 & 3.1648 & 2.5829 & 2.6918 & 3.8547 & 4.0130 \\
\cline { 2 - 8 } & $\max \left(\sigma_{T_{o}}\right)$ & 3.8264 & 3.9838 & 4.1111 & 4.2808 & 5.6120 & 5.6201 \\
\cline { 2 - 8 } & $\min \left(\sigma_{T_{o}}\right)$ & 1.6956 & 1.7660 & 1.4095 & 1.4680 & 2.3852 & 2.4826 \\
\hline
\end{tabular}

\subsection{Simulation of fluid velocity and pressure under variable working conditions}

Streams to and from the heat exchanger enter and leave by means of header and nozzle. The ends of header and inclination of nozzle have crucial influences on 
uniform fluid distribution, especially for large PFHE. The fluid velocity and pressure inside header under three working conditions is shown in Fig.10.
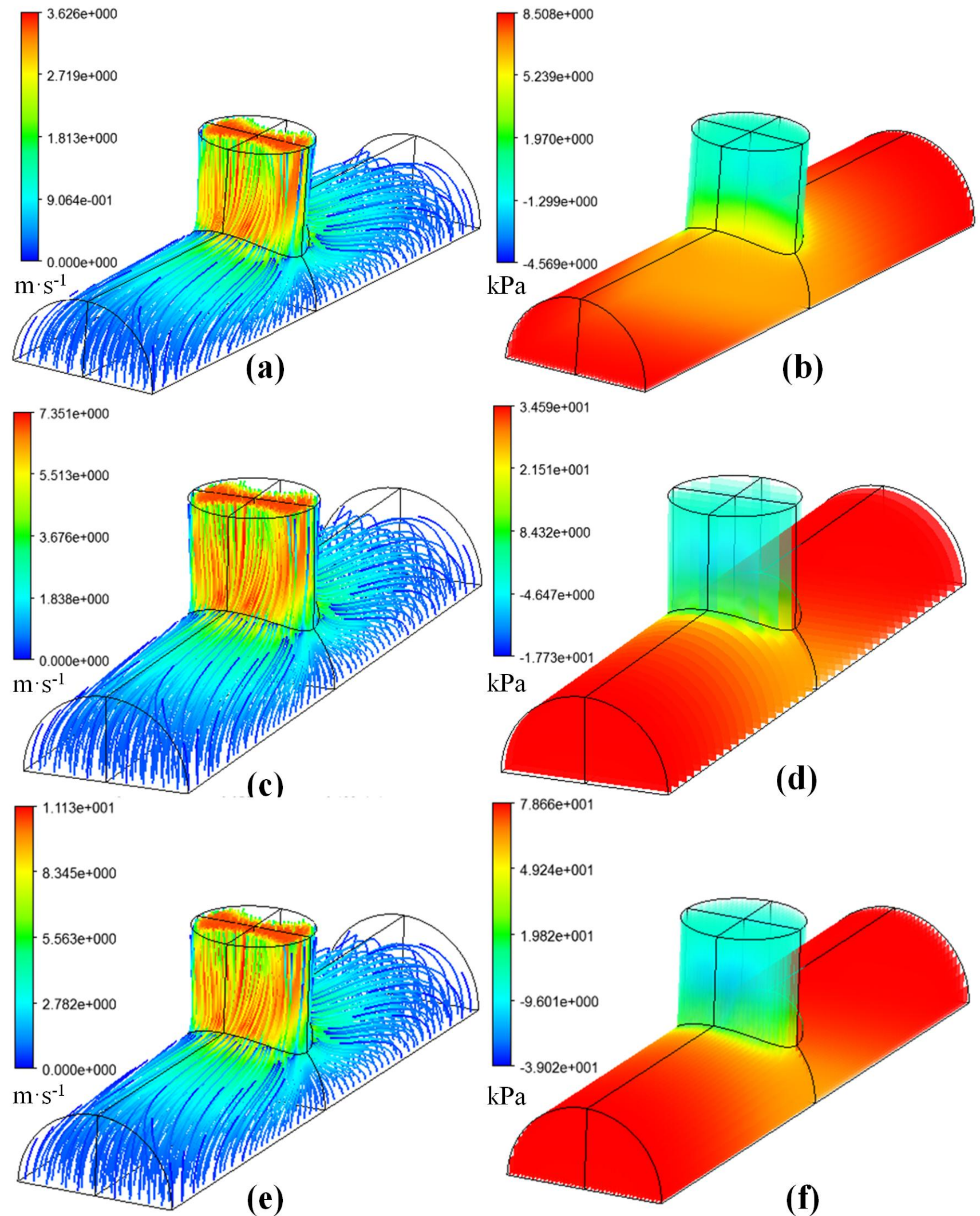

(b)
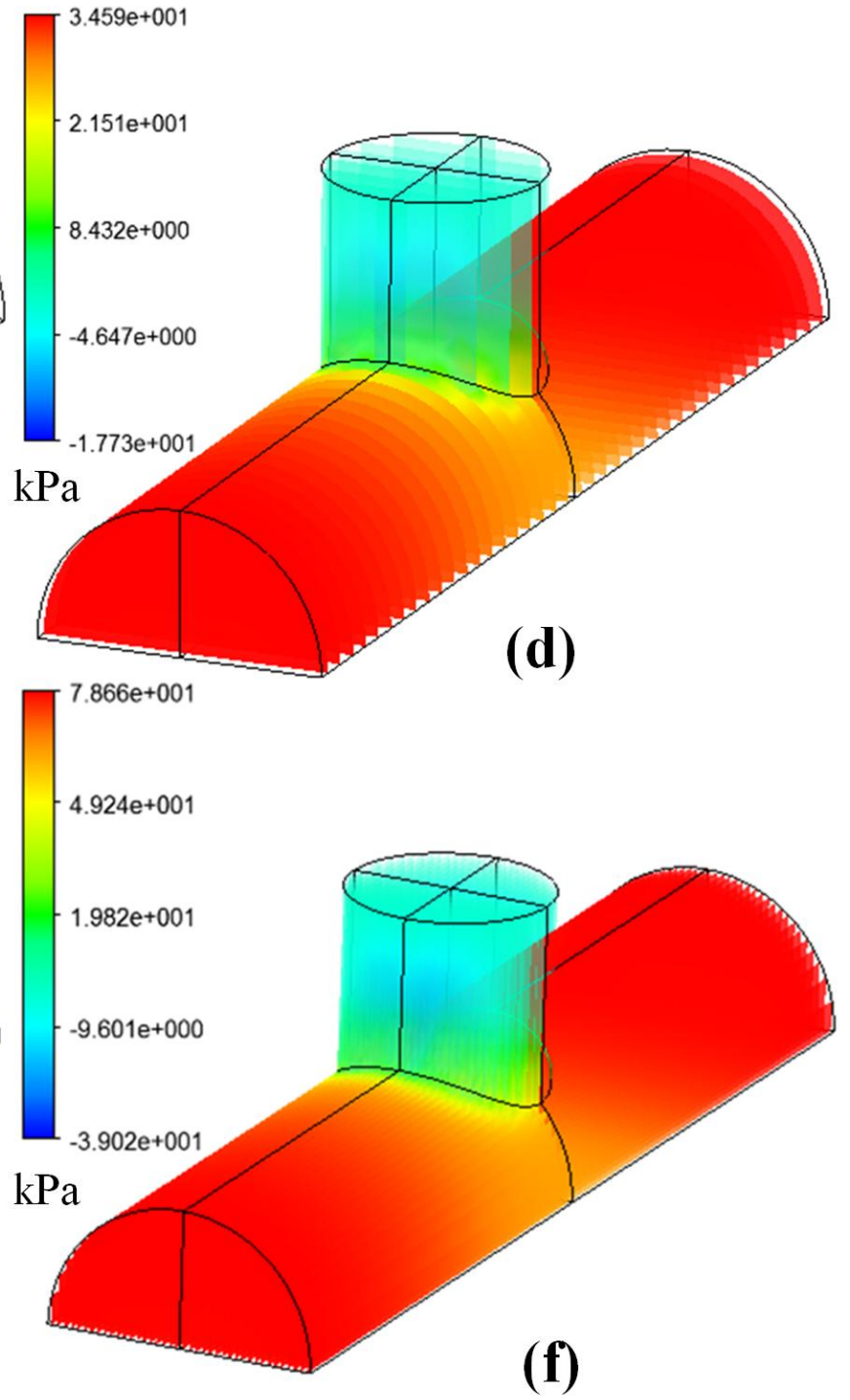

Fig.10. Fluid velocity and pressure inside header of type6 fins under three working conditions where (a) is at $\mathrm{Re}=1000$; (b) is at $\mathrm{Re}=2027$; and (c) is at $\mathrm{Re}=3070$. 
As shown in Fig.10, the maximum fluid velocity $u$ is increased with the increasing of Re under three working conditions. $u=3.626 \mathrm{~m} \cdot \mathrm{s}^{-1}$ at $\operatorname{Re}=1000$ is shown in (a); $u=7.351 \mathrm{~m} \cdot \mathrm{s}^{-1}$ at $\operatorname{Re}=2027$ is shown in (b); $u=1.113 \mathrm{e} 1 \mathrm{~m} \cdot \mathrm{s}^{-1}$ at $\operatorname{Re}=3070$ is shown in (c). The pressure $P$ is also increased with the increasing of Re under three working conditions. $P=805.8 \mathrm{kPa}$ at $\mathrm{Re}=1000$ is shown in (a); $P=3.459 \mathrm{e} 1 \mathrm{kPa}$ at $\operatorname{Re}=2027$ is shown in (b); $P=7.866 \mathrm{e} 1 \mathrm{kPa}$ at $\mathrm{Re}=3070$ is shown in (c). The simulation results are consistent with the experimental results.

The comparisons of the proposed MDE method with previously published studies are shown in Table 4.

Table 4 Comparisons of the methods with previously published studies

\begin{tabular}{|c|c|c|}
\hline Comparative Items & $\begin{array}{l}\text { Previously published } \\
\text { studies }\end{array}$ & The proposed MDE method \\
\hline $\begin{array}{l}\text { Number of streams in each } \\
\text { thermal equilibrium }\end{array}$ & $2^{[9]}$ & More than two streams shown in Eq.(58) \\
\hline Effective heat transfer distance & Half fin height ${ }^{[9]}$ & More than half fin height shown in Eq.(60) \\
\hline Phase state of multi streams & Single-phase ${ }^{[29]}$ & Considering phase change shown in Eq.(72) \\
\hline The total number of passages & $14^{[31]}$ & $\begin{array}{l}\text { More than } 14 \text { shown in Fig.5, Fig.6 using } \\
\text { Eq.(36) }\end{array}$ \\
\hline Number of multi streams & $\begin{array}{l}1 \text { hot stream and } 3 \text { cold } \\
\text { streams }^{[31]}\end{array}$ & $\begin{array}{c}2 \text { hot streams and } 4 \text { cold streams shown in } \\
\text { Fig.5, Fig.6 }\end{array}$ \\
\hline $\begin{array}{l}\text { Outlet temperature } \\
\text { inhomogeneity }\end{array}$ & $4.1 \%{ }^{[31]}$ & $29.59 \%$ shown in Fig.6 \\
\hline Type of fin & Serrated fin ${ }^{[32]}$ & $\begin{array}{l}\text { Plain fin, serrated fin and wavy fin shown in } \\
\text { Table. } 1\end{array}$ \\
\hline Number of working conditions & One ${ }^{[24]}$ & More than one shown in Fig.8,Fig.9,Fig.10 \\
\hline
\end{tabular}

The fin parameters are finally determined according to the adaptability to the working conditions by comparing six different fins and cores. According to Eq.(77), 
the total heat transfer coefficient of large PFHE is increased from $2365 \mathrm{~W} \cdot \mathrm{m}^{-2} \cdot \mathrm{K}^{-1}$ to $2879 \mathrm{~W} \cdot \mathrm{m}^{-2} \cdot \mathrm{K}^{-1}$ with ratio of $21.73 \%$ using the proposed MDE method.

\section{Conclusions}

(1) Multiple Dynamic Equilibriums (MDE) is proposed to complete design of large PFHE. The large heat transfer area in plane perpendicular to the flowing direction is divided into MDE according to the temperature difference sequence between the one-sided adjacent streams. The MDE is not based on the assumption that there exist thermal equilibrium between the two adjacent streams. Therefore, MDE is applicable for various stacking patterns of hot and cold streams.

(2) The heat transfer process about Re is divided into MDE according to the dynamic equilibriums between heat transfer and frictional resistance to determine the optimal fins under different working conditions. It is especially useful for the condition that Renault number of multi-streams fluctuates in wide range which generates various working conditions.

(3) The experiment of heat transfer and flow resistance is completed to determine heat transfer factor and flow resistance factor under different Reynolds number. The proposed method is especially useful for thermal design of large energy-efficient PFHE for ASU.

\section{ACKNOWLEDGEMENTS}

The work presented in this article is funded by the National Basic Research Program (973) of China (No. 2011CB706506), National Science Foundation of China (No. 51375012; 51490663; 51521064), 863 Research Project of China (No.2013AA041303) and Zhejiang Provincial Natural Science Foundation of China (LY13E050007).

\section{REFERENCES}

[1] Mathew A., Wang M., Potential for improving the energy efficiency of cryogenic air separation unit (ASU) using binary heat recovery cycles, Appl. Therm. Eng. 81(2015) 223-231.

[2] Tong L., Zhang A., Li Y., Yao L., Wang L., Li H., Li L., Ding Y., Exergy and energy analysis of a load regulation method of CVO of air separation unit, Appl. Therm. Eng. 80 (2015) 413-423. 
[3] H. Najafi, B. Najafi, P. Hoseinpoori, Energy and cost optimization of a plate and fin heat exchanger using genetic algorithm, Appl. Therm. Eng. 31(10) (2011) 1839-1847.

[4] R.J. Goldstein, W.E. Ibele, S.V. Patankar, T.W. Simon, T.H. Kuehn, P.J. Strykowski, K.K. Tamma, J.V.R. Heberlein, J.H. Davidson, J. Bischof, F.A. Kulacki, U. Kortshagen, S. Garrick, V. Srinivasan, K. Ghosh, R. Mittal, Heat transfer-A review of 2005 literature, Int. J. Heat Mass Transfer 53(21-22) (2010) 4397-4447.

[5] J.C. Pacio, C.A. Dorao, A review on heat exchanger thermal hydraulic models for cryogenic applications, Cryogenics 51 (7) (2011) 366-379.

[6] Das, Prasanta Kumar; Ghosh, Indranil. Thermal design of multistream plate fin heat exchangers-a state-of-the-art review, Heat Transfer Eng. 33(4-5) (2012)284-300.

[7] Wang Z, Li Y. Layer pattern thermal design and optimization for multistream plate-fin heat exchangers-A review, Renew. Sust. Energ. Rev. 53 (2016) 500-514.

[8] Prasad BSV. The Performance Prediction of multistream plate-fin heat exchangers based on stacking pattern, Heat Transfer Eng. 12(4) (1991)58-70.

[9] Prasad BSV. Fin efficiency and mechanisms of heat exchange through fins in multi-stream plate-fin heat exchangers: development and application of a rating algorithm, Int. J. Heat Mass Transfer 40(18) (1997) 4279-4288.

[10] S. Ghosh, I. Ghosh, D. Pratihar, B. Maiti, P. Das, Optimum stacking pattern for multi-stream plate-fin heat exchanger through a genetic algorithm, Int. J. Therm. Sci. 50 (2011) 214-224.

[11] M. Zhao, Y. Li, An effective layer pattern optimization model for multi-stream plate-fin heat exchanger using genetic algorithm, Int. J. Heat Mass Transfer 60 (2013) 480-489.

[12] W. Sha, C. Yang, T. Kao, S. Cho, Multidimensional numerical modeling of heat exchanger, Int. J. Heat Fluid Flow 23 (2002) 222-231.

[13] M. Hasan, I.A. Karimi, H.E. Alfadala, H. Grootjans, Operational modeling of multistream heat exchangers with phase changes, AlChE J. 55 (1) (2009) 150-171.

[14] H. Hajabdollahi, M. Tahani, M.H.S. Fard, CFD modeling and multi-objective optimization of compact heat exchanger using CAN method, Appl. Therm. Eng. 31 (2011) 2597-2604.

[15] Y Zhu,Y Li, Three-Dimensional numerical simulation on the laminar flow and heat transfer in four basic fins of Plate-Fin Heat Exchangers, J Heat Trans-T ASME 130(11) (2008) 111801-8.

[16] M. Speetjens, A.V. Steenhoven, Visualisation of heat transfer in 3D unsteady flows, Int. J. Therm. Sci. 49(7) (2010) 1103-1114.

[17] J. Wen, Y. Li, S. Wang, A. Zhou, Experimental investigation of header configuration improvement in plate-fin heat exchanger, Appl. Therm. Eng. 27 (2007) 1761-1770.

[18] T.S. Khan, M.S. Khan, M.C. Chyu, Z.H. Ayub, Experimental investigation of single phase convective heat transfer coefficient in a 
corrugated plate heat exchanger for multiple plate configurations, Appl. Therm. Eng. 30(8-9) (2010) 1058-1065.

[19] I. Gherasim, M. Taws, N. Galanis, T.N. Cong, Heat transfer and fluid flow in a plate heat exchanger part I. Experimental investigation, Int. J. Therm. Sci. 50(8) (2011) 1492-1498.

[20] I. Kotcioglu, A. Cansiz, M. Nasiri Khalaji, Experimental investigation for optimization of design parameters in a rectangular duct with plate-fins heat exchanger by Taguchi method, Appl. Therm. Eng. 50 (2013) 604-613.

[21] I. Ghosh, S.K. Sarangi, P.K. Das, An alternate algorithm for the analysis of multistream plate fin heat exchangers, Int. J. Heat Mass Transfer 49(17-18) (2006) 2889-2902.

[22] J.M. Reneaume, N. Niclout, Plate fin heat exchanger design using simulated annealing, Computer Aided Chemical Engineering, 9 (2001) 481-486.

[23] H. Peng, X. Ling, Optimal design approach for the plate-fin heat exchangers using neural networks cooperated with genetic algorithms, Appl. Therm. Eng. 28 (2008) 642-650.

[24] H. Najafi, B. Najafi, Multi-objective optimization of a plate and frame heat exchanger via genetic algorithm, Heat Mass Transfer. 46 (6) (2010) 639-647.

[25] M. Yousefi, A.N. Darus, H. Mohammadi. An imperialist competitive algorithm for optimal design of plate-fin heat exchangers, Int. J. Heat Mass Transfer 55(11-12) (2012) 3178-3185.

[26] M. Yousefi, R. Enayatifar, A.N. Darus, A.H. Abdullah, Optimization of plate-fin heat exchangers by an improved harmony search algorithm, Appl. Therm. Eng. 50 (2013) 877-885.

[27] H. Zarea, F. M. Kashkooli, A. M. Mehryan, M. R. Saffarian, E. N. Beherghani, Optimal design of plate-fin heat exchangers by a Bees Algorithm, Appl. Therm. Eng. 69(1-2) (2014) 267-277.

[28] M. Hajmohammadi, M. Rahmani, A. Campo, O. Joneydi Shariatzadeh, Optimal design of unequal heat flux elements for optimized heat transfer inside a rectangular duct, Energy 68 (2014) 609-616.

[29] M. Montanez-Morantes, M. Jobson, Zhang N., Available online design and simulation of multistream plate-fin heat exchangers-single-phase streams, Appl. Therm. Eng. 92(5) (2016) 172-186.

[30] O. E. Turgut, Hybrid chaotic quantum behaved particle swarm optimization algorithm for thermal design of plate fin heat exchangers, Appl. Math. Model. 40(1) (2016) 50-69.

[31] Tian Q, He G, Zhao L, Cai D, Chen L. Passage arrangement optimization of multi-stream plate-fin heat exchangers, Appl. Therm. Eng. 73 (2014) 963-974.

[32] J. Wen, H. Yang, X. Tong, K. Li, S. Wang, Y. Li, Configuration parameters design and optimization for plate-fin heat exchangers with serrated fin by multi-objective genetic algorithm, Energ. Convers. Manage. 117(2016) 482-489. 


\section{NOMENCLATURE}

$A=$ cross-section area, $m^{2}$

$A_{1}=$ primary heat surface area, $m^{2}$

$A_{2}=$ secondary heat surface area, $m^{2}$

$A_{e}=$ effective heat surface area per meter, $\mathrm{m}^{2}$

$C_{P}=$ mass specific heat capacity at constant pressure, $\mathrm{J} \cdot \mathrm{kg}^{-1} \cdot \mathrm{K}^{-1}$

$d_{e}=$ equivalent diameter, $\mathrm{mm}$

$d_{f}=$ fin density, $m^{-1}$

$f=$ fanning friction factor $(f$-factor $)$

$h_{e}=$ effective heat transfer distance $(m)$

$h_{f}=$ fin height/ inside height, $\mathrm{mm}$

$\dot{H}=$ mass specific enthalpy, $\mathrm{J}^{\mathrm{kg}}{ }^{-1}$

$j=$ heat transfer factor ( $j$-factor)

$\lambda=$ thermal conductivity, $\mathrm{W} \cdot \mathrm{m}^{-1} \cdot \mathrm{K}^{-1}$

$m=$ mass of substance, $\mathrm{kg}$

$N_{E}=$ number of streams in equilibrium

$p_{f}=$ Fin pitch/spacing, $\mathrm{m}$

$P=$ pressure, $\mathrm{Pa}$

$q=$ heat transfer rate, $\mathrm{W}$

$q_{A}=$ heat flux, $\mathrm{W} \cdot \mathrm{m}^{-2}$

$q_{m}=$ mass flux per unit area, $\mathrm{kg} \cdot \mathrm{m}^{-2} \cdot \mathrm{s}^{-1}$

$Q=$ heat transfer quantity, $\mathrm{J}$

$R e=$ Reynolds number

$t_{f}=$ fin thickness, $\mathrm{mm}$

$T$ = temperature, $\mathrm{K}$

$T_{c, i}, T_{c, o}=$ cold fluid terminal temperatures (inlet, outlet), $\mathrm{K}$

$T_{h, i}, T_{h, o}=$ hot fluid terminal temperatures (inlet, outlet), $\mathrm{K}$ 
$K=$ heat transfer coefficient, $\mathrm{W} \cdot \mathrm{m}^{-2} \cdot \mathrm{K}^{-1}$

$K_{\alpha}=$ is convective heat transfer coefficient, $\mathrm{W} \cdot \mathrm{m}^{-2} \cdot \mathrm{K}^{-1}$

$u=$ fluid velocity, $\mathrm{m} \cdot \mathrm{s}^{-1}$

$v=$ kinematic viscosity, $\mathrm{m}^{2} \cdot \mathrm{s}^{-1}$

$\dot{V}=$ volume flow rate of stream $\left(\mathrm{N} \mathrm{m}^{3} \cdot \mathrm{s}^{-1}\right)$

$\Delta H=$ enthalpy change, $\mathrm{J} \cdot \mathrm{kg}^{-1}$

$\Delta P=$ pressure drop, $\mathrm{Pa}$

$\Delta T=$ temperature change, $\mathrm{K}$

$\varepsilon=$ Thermal efficiency

$\eta_{f}=$ Fin efficiency

$\eta_{s}=$ Surface efficiency

$\mu=$ dynamic viscosity, $\mathrm{Pa} \cdot \mathrm{s}$

$\rho=$ mass density of a stream, $\mathrm{kg} \cdot \mathrm{m}^{-3}$

\section{SUBSCRIPTS}

c cold

h hot

i inlet

o outlet 


\section{BIOGRAPHICAL NOTES}

$\mathrm{Xu}$ Jinghua, born in 1979, is currently an associate professor in mechanical engineering college, Zhejiang University, China. He received his Ph.D. from Zhejiang University, China, in 2009. His research interests include thermal engineering.

E-mail: xujh@zju.edu.cn

Chen Xiaojie, born in 1990, is currently a Master Degree Candidate in mechanical engineering college, Zhejiang University, China. His research interests include CAE.

E-mail: 21525096@zju.edu.cn

Zhang Shuyou, born in 1963, is currently a professor and a Ph.D. supervisor in mechanical engineering college, Zhejiang University, China. He received his Ph.D from Zhejiang University, China, in 1999. His research interests include CAD.

E-mail: zsy@zju.edu.cn

Chen Qianyong, born in 1992, is currently a Ph.D. Candidate in mechanical engineering college, Zhejiang University, China. His research interests include CAD.

E-mail: 11625067@zju.edu.cn

Gou Huawei, born in 1995, is currently a Master Degree Candidate in mechanical engineering college, Zhejiang University, China. His research interests include CAD.

E-mail: 21625214@zju.edu.cn

Tan Jianrong, born in 1954, is currently an academician of Chinese Academy of Engineering and a professor of mechanical engineering college, Zhejiang University, China. He received his Ph.D. from Zhejiang University, China, in 1992. His research interests include product design 
methodology.

E-mail: egi@zju.edu.cn 